\title{
IMPACTO DE LAS LEYES DE COMUNICACIÓN DE ECUADOR Y VENEZUELA EN EL EJERCICIO DE LA LIBERTAD DE EXPRESIÓN, A PARTIR DE 6 CASOS EMBLEMÁTICOS
}

\section{Impact of the communication laws of Ecuador and Venezuela on the exercise of freedom of expression, from 6 emblematic cases}

\author{
Luisa Torrealba Mesa \\ Universidad Central de Venezuela \\ luisa.torrealba@ucv.ve
}

Fecha de recepción del artículo: 23/06/2017

Fecha de aceptación definitiva: 30/10/2017

\begin{abstract}
El presente artículo fue realizado en el marco del proyecto: "Impulso a la investigación académica en temas de periodismo y libertad de expresión en Ecuador y Latinoamérica", que inició en marzo de 2017 y culminó en septiembre de 2017 y fue financiado por el Foro de Periodistas de Ecuador (FOPE).

2 Licenciada y Magister Scientiarum en Comunicación Social, por la Universidad Central de Venezuela (UCV), Caracas, Venezuela. Investigadora docente del Instituto de Investigaciones de la Comunicación, de la Facultad de Humanidades y Educación de la Universidad Central de Venezuela (UCV), en la Línea de Investigación Comunicación Política y Políticas de Comunicación. Número ORCID: 0000-0001-7739-0367. Camilo Molina es profesor de Sociología de la Facultad de Comunicación, Artes y Humanidades de la Universidad Tecnológica Equinoccial. Estudiante del doctorado de ciencias sociales de la Universidad de Salamanca. Fernanda Cevallos, periodista de la Universidad Tecnológica Equinoccial del Ecuador. Maritza Palma, periodista de la Universidad Católica de Pereira, participó como investigadora de apoyo.
\end{abstract}




\section{RESUMEN}

La investigación tuvo como objetivo diagnosticar cuál ha sido el impacto de la Ley Orgánica de Comunicación (Ecuador) y la Ley de Responsabilidad Social en Radio, Televisión y Medios Electrónicos (Venezuela) en el ejercicio de la libertad de expresión, de acuerdo a los estándares internacionales de derechos humanos. Se partió de la hipótesis de que ambas leyes han limitado el ejercicio del derecho de la libertad de expresión. Se empleó el tipo de investigación documental, con un enfoque cuantitativo y la técnica del análisis de contenido. Se revisaron seis casos emblemáticos (tres de Ecuador y tres de Venezuela), a partir del análisis de las leyes y las resoluciones o decisiones de los órganos reguladores encargados de aplicarlas; los reportes de organizaciones no gubernamentales que monitorean la libertad de expresión, en ambos países, y de las piezas comunicacionales correspondientes a los casos estudiados. El análisis partió de las siguientes variables: garantías y restricciones para el derecho establecidos en las leyes, sujetos de aplicación, órganos responsables, interés público de los asuntos abordados en las piezas comunicacionales estudiadas, limitaciones legítimas a la libertad de expresión consagradas en la Convención Americana de Derechos Humanos, fundamentos legales y prohibiciones contenidas en las resoluciones oficiales de los casos, tipos de violaciones a la libre expresión y consecuencias.

Palabras clave: Libertad de expresión; leyes; comunicación; Ecuador; Venezuela.

\section{ABSTRACT}

The objective of the research was to diagnose the impact of the Ley Orgánica de Comunciación (Ecuador) and the Ley de Responsabilidad Social en Radio, Televisión y Medios Electrónicos (Venezuela) in the exercise of freedom of expression, according to the standards international human rights. It was assumed that both laws have limited the exercise of the right to freedom of expression. The type of documentary research was used, with a quantitative approach and the technique of content analysis. Six emblematic cases were reviewed (three from Ecuador and three from Venezuela), based on an analysis of the laws and resolutions or decisions of the regulatory bodies responsible for applying them; the reports of non-governmental organizations that monitor the freedom of expression in both countries and of the communication pieces corresponding to the cases studied. The analysis started from the following variables: guarantees and restrictions for the law established in the laws, subjects of application, responsible bodies, public interest of the issues addressed in the 
communication pieces studied, legitimate limitations to freedom of expression enshrined in the American Convention of Human Rights, legal foundations and prohibitions contained in the official resolutions of the cases, types of violations of free expression and consequences.

Key words: Freedom of expression; laws; communication; Ecuador; Venezuela.

\section{Introducción}

Para el ejercicio pleno de la libertad de expresión es necesario que el Estado adopte y respete las normas establecidas por el derecho internacional, para garantizar un libre flujo de información y la posibilidad de que todos los ciudadanos puedan expresar sus ideas, opiniones y críticas (Pinto, 2000). En el continente americano, el principal instrumento de Derechos Humanos es la Convención Americana de Derechos Humanos, suscrita el 28 de noviembre de 1969, que establece garantías para el resguardo de este derecho.

La libertad de expresión es un derecho humano fundamental, que incluye "la libertad de buscar, recibir y difundir informaciones e ideas de toda índole" y que "no puede estar sujeto a previa censura sino a responsabilidades ulteriores" (OEA, 1969, s/p).

En función de garantizar un ejercicio pleno del derecho, la convención plantea que las condiciones para la aplicación del principio de "responsabilidad ulterior" deben estar "expresamente fijadas por la ley" y deben asegurar: "a) el respeto a los derechos o a la reputación de los demás, o b) la protección de la seguridad nacional, el orden público o la salud o la moral públicas" (OEA, 1969, $\mathrm{s} / \mathrm{p}$ ); para garantizar la difusión de informaciones y el intercambio libre y plural de ideas, en un marco de respeto, sin que prevalezcan los criterios particulares de las autoridades.

Otra importante garantía que contempla la convención, en el numeral 3 de su artículo 13, es la prohibición de "vías o medios indirectos" para limitar la libertad de expresión (OEA, 1969, s/p), entre los que caben las presiones de orden económico contra medios de comunicación. Prohíbe las incitaciones al odio o a la discriminación de las personas, en función de hacer prevalecer el respeto, la tolerancia y la pluralidad necesarios en los sistemas democráticos, en los siguientes términos: 


\section{Impacto de las leyes de comunicación de Ecuador y Venezuela en el}

ejercicio de la libertad de expresión, a partir de 6 casos emblemáticos

Establece también, en el artículo 14, el derecho a "rectificación", que permite a los ciudadanos que se sientan afectados por informaciones inexactas 0 agraviantes emitidas a través de medios de comunicación, dar una respuesta.

En los ámbitos nacionales, en un primer nivel, las constituciones contienen disposiciones generales sobre las cuales se establecen las bases para la conformación de un Estado y para la formulación de las políticas públicas.

En un segundo nivel se encuentran el conjunto de leyes vigentes en un país, que según Janeth Kelly (2003, p.72) constituyen "el mecanismo básico para fijar los lineamientos de las políticas públicas".

Tanto en Ecuador como en Venezuela, los textos constitucionales consagran garantías para el derecho a la libertad de expresión, en sus artículos 384 y 57, respectivamente. Ambas constituciones fueron elaboradas en el contexto de cambios sociopolíticos, en ambas naciones, iniciados por los expresidentes Rafael Correa ${ }^{1}$ y Hugo Chávez ${ }^{2}$. Los dos mandatarios arribaron al poder con proyectos de gobierno que prometían igualdad, reivindicación y dignificación de los sectores de la población más empobrecida y programas sociales de tipo asistencialista. El gobierno de Correa se denominó la "Revolución Ciudadana" y el de Chávez la "Revolución Bolivariana"; ambos procesos, en sus inicios, impulsaron nuevas constituciones nacionales.

Además de estas afinidades políticas, ambos países comparten otros elementos comunes: en sus territorios está presente la cordillera de Los Andes y Simón Bolívar fue un actor fundamental para la consecución de la independencia de estas naciones.

"En la región andina se ha puesto mucho énfasis sobre la forma conflictiva en que se ha procedido a cambiar constituciones en aquellos países donde han surgido líderes nuevos que han llamado a una refundación del país" (Munck, 2010, p. 156). Los casos de Venezuela y Ecuador son ilustrativos de las tensiones internas generadas entre los nuevos proyectos políticos y sus líderes con sectores políticos de oposición, empresarios y representantes de la sociedad civil.

El ecosistema de los medios de comunicación de Ecuador y Venezuela también fue alcanzado por la conflictividad. Radioemisoras, televisoras, publicaciones impresas y páginas web informativas, que mantenían líneas editoriales críticas hacia la gestión de Chávez y Correa, eran consideradas por

\footnotetext{
${ }^{1}$ Rafael Correa ejerció la presidencia del Ecuador desde el 15 de enero de 2007 hasta el 24 de mayo de 2017.

${ }^{2}$ Hugo Chávez ejercició la presidencia de Venezuela entre el 2 de febrero de 1999 y el 5 de marzo de 2013, cuando falleció debido a un cáncer. Fue sucedido en el poder por su pupilo y compañero de partido, Nicolás Maduro.
} 
Impacto de las leyes de comunicación de Ecuador y Venezuela en el

ejercicio de la libertad de expresión, a partir de 6 casos emblemáticos estos líderes como adversarios; lo que derivó en acciones que impactaron en el ejercicio de la libertad de expresión y en las democracias de estas naciones.

El libre y plural flujo de ideas y opiniones es necesario para que los ciudadanos estén bien informados y puedan tomar las decisiones que les

permitan participar activamente en la vida pública y en la construcción de la democracia (Corte Interamericana de Derechos Humanos, 1985, p. 20). Así, para que haya una sólida y robusta democracia es necesario que existan plenas garantías para el ejercicio de la libertad de expresión, que deben estar expresadas en los textos constitucionales y en los marcos legales nacionales. Ello implica que las leyes garanticen el disfrute pleno del derecho, sin que quien lo ejerza tenga consecuencias negativas para el disfrute de sus libertades y su integridad personal. No pueden existir limitaciones para este derecho, salvo las restricciones legítimas señaladas en los instrumentos internacionales de derechos humanos, para proteger la salud, la moral pública, la dignidad honra y reputación de las personas, y la seguridad nacional.

Los gobernantes están llamados a garantizar el disfrute de la libre expresión y la contraloría que llevan a cabo los medios de comunicación social, como parte del ejercicio de este derecho. Gobernar democráticamente es un proceso "que no suprime o evade el sistema de frenos y contrapesos en la relación entre presidentes y congresos que las constituciones latinoamericanas, con variaciones, avalan" (Munck, 2010, p. 156). Las leyes son los espacios naturales en los que se consagran los fundamentos de estos sistemas de contrapesos o contraloría.

Mientras los textos constitucionales de Ecuador y Venezuela contemplan el respeto a la libre expresión, el marco legal de ambos países, en materia de comunicación, se sustenta en una racionalidad punitiva y sancionatoria, que difiere de las garantías establecidas en las cartas magnas. De allí que se consideró pertinente abordar como problema y pregunta de investigación: ¿cuál ha sido el impacto de la Ley de Comunicación (Ecuador) y la Ley de Responsabilidad Social en Radio, Televisión y Medios Electrónicos (Ley RESORTE), en el ejercicio de la libertad de expresión, en los países de origen de ambas normativas? Para verificar, mediante casos concretos, cómo se han aplicado las sanciones establecidas en la ley y el efecto que han tenido para el ejercicio del derecho.

La Relatoría para la Libertad de Expresión de la OEA ha advertido que la Ley Orgánica de Comunicación (LOC), aprobada por la Asamblea Nacional de 


\section{Impacto de las leyes de comunicación de Ecuador y Venezuela en el}

ejercicio de la libertad de expresión, a partir de 6 casos emblemáticos

Ecuador, en junio de 2013, tiene "un amplio margen de discreción que le otorga a la autoridad de aplicación para restringir contenidos difundidos por medios de comunicación" (Lanza, 2016, p. 188).

La LOC incluye disposiciones que podrían limitar el derecho a la libre expresión, tanto de forma directa como indirecta. "La ambigüedad en los términos de las restricciones y la cuantía exorbitante de las sanciones impuestas podrían generar un efecto amedrentador en el ejercicio del derecho a la libertad de expresión en Ecuador" (Lanza, 2016, p. 188).

En relación con Ley RESORTE, aprobada en 2005 y reformada en 2010, la Relatoría para la Libertad de Expresión de la OEA ha advertido que su autoridad de aplicación no es independiente y ha hecho exhortos para que "la regulación del sector, la apertura de los procedimientos administrativos y la eventual imposición de sanciones en el marco de dicho instrumento estén a cargo de órganos imparciales e independientes del poder ejecutivo" (Botero, 2010, p. 177).

La reforma a la que fue sometida la Ley en 2010 amplió su aplicación a "medios electrónicos" y aumentó las prohibiciones "al incorporar una serie de restricciones que resultan de enorme amplitud y ambigüedad; y hace más drásticas las sanciones por violación de tales prohibiciones, entre otras consideraciones" (Botero, 2010, p. 179).

En este contexto, la presente investigación tuvo como objetivo diagnosticar el impacto que han tenido la LOC (Ecuador) y la Ley RESORTE (Venezuela), en el ejercicio de la libertad de expresión, a partir de la revisión de 6 casos emblemáticos. También, se propuso determinar si las disposiciones sobre el ejercicio de la libertad de expresión en la LOC y la Ley RESORTE fueron coherentes con las disposiciones constituciones de estos países para garantizar este derecho.

La LOC establece garantías para los derechos a la comunicación y las libertades de expresión y opinión. Contempla el derecho a la rectificación para las personas que sean afectadas por informaciones difundidas en los medios de comunicación, que tengan fallas de "verificación, contrastación y precisión" (artículo 23). Su aplicación incluye a todos los medios de comunicación (radio, televisión e impresos) (Asamblea Nacional de Ecuador, 2013).

También plantea la posibilidad de aplicar censura previa en caso de estados de excepción, con lo que contraviene los estándares internacionales de derechos humanos, que la prohíben. Los órganos responsables de monitorear los posibles incumplimientos de la ley y aplicar las sanciones correspondientes son el Consejo de Regulación y Desarrollo de la Información y Comunicación y la Superintendencia de la Información y Comunicación (SUPERCOM). 
La ley venezolana (Asamblea Nacional de la República Bolivariana de Venezuela, 2011) contempla entre sus objetivos el respeto a la libertad de expresión e información, sin censura. Incluye además, en sus garantías, el respeto a los derechos humanos y propicia la producción de contenidos adecuados para niños y adolescentes. Esta ley abarca a medios de comunicación radiofónicos, televisivos y electrónicos. Los órganos responsables de su aplicación son la Comisión Nacional de Telecomunicaciones (CONATEL), adscrita al Ministerio del Poder Popular para la Comunicación y la Información, y el Directorio de Responsabilidad Social, ente colegiado cuya mayoría de miembros (8 de 12) son designados por el Poder Ejecutivo.

Las hipótesis manejadas para la investigación fueron las siguientes: 1) La LOC y la Ley RESORTE han limitado el ejercicio del derecho de la libertad de expresión en sus respectivos países. 2) Las disposiciones sobre el ejercicio de la libertad de expresión, contenidas en ambas leyes, no son coherentes con las garantías establecidas en las constituciones de estos países para garantizar este derecho.

Para intentar corroborar estas hipótesis se partió de la concepción de la libertad de expresión, como un derecho humano bidireccional, que permite a los ciudadanos expresarse y tener acceso a otras expresiones (Huerta, 2002).

Quienes están bajo la protección de la Convención Americana de Derechos Humanos tienen el derecho de expresar su propio pensamiento y la libertad de buscar, recibir y difundir informaciones e ideas de diversas (Huerta, 2002, p. 17). Esto incluye a aquellas expresiones que puedan resultar críticas o incómodas para quienes ejercen el poder.

Por otro lado, la libertad de expresión tiene una dimensión individual y una colectiva. "Cuando se restringe ilegalmente la libertad de expresión de un individuo, no solo es el derecho de ese individuo el que está siendo violado, sino también el derecho de todos a recibir informaciones e ideas" (Huerta, 2002, p. 17). Cuando se limitan contenidos emitidos por medios de comunicación masiva se afectan ambas dimensiones: la de los individuos que producen los contenidos y las de los grupos de ciudadanos que conforman las audiencias de esos contenidos.

Ambas dimensiones, la individual y la colectiva, deben ser garantizadas de forma simultánea para que pueda hacer un nutrido intercambio de ideas y opiniones que alimenten el debate público, necesario para la democracia. 


\section{Impacto de las leyes de comunicación de Ecuador y Venezuela en el} ejercicio de la libertad de expresión, a partir de 6 casos emblemáticos

Réniz (2002, p. 36) refuerza la importancia de estas dos dimensiones del derecho al recordar que la libertad de expresión "no constituye solo un derecho individual, dado que pertenece también a los ciudadanos, porque está en juego el debate público sobre los asuntos de interés general; el pluralismo y la libertad de opinar sobre los asuntos públicos". La acotación de la autora resulta relevante, toda vez porque la mayoría de los casos analizados en la presente investigación refieren a asuntos vinculados con el ejercicio de la gestión pública, tanto en Ecuador como en Venezuela.

\section{Metodología}

Se trata de una investigación de tipo documental, con un enfoque cuantitativo, que parte de la técnica del análisis de contenido y examina las piezas comunicacionales (audiovisuales e impresas), a partir de categorías organizadas en cinco cuadros, que permiten observar, de forma estructurada, los siguientes aspectos: 1) Garantías, restricciones y prohibiciones contempladas en la LOC (Ecuador) y en la Ley RESORTE (Venezuela). 2) Características de las informaciones contenidas en las piezas comunicacionales estudiadas (tipo de publicación, abordaje de asuntos de interés público, referencia a autoridades públicas/gobierno). 3) Presencia de contenido tipificado como limitación legítima a la libertad de expresión, en las piezas comunicacionales estudiadas. 4) Respeto a los estándares de libertad de expresión contenidos en la Convención Americana de Derechos Humanos, en los casos estudiados. 5) Impacto de las resoluciones de los casos, emitidas por las autoridades competentes, para el derecho a la libertad de expresión.

La metodología propuesta permitió examinar tres casos de estudio de Ecuador y tres de Venezuela referidos a periodistas, medios de comunicación o ciudadanos que fueron sancionados o impedidos de ejercer plenamente su derecho a la libre expresión, por la aplicación de estas leyes. Además, se identificaron las causas y argumentos esgrimidos por las autoridades en dichos casos y sus efectos en el ejercicio de las libertades informativas.

Se realizó una revisión de los artículos relacionados con el ejercicio de la libertad de expresión y se estudiaron las consecuencias de su aplicación para el ejercicio de este derecho.

De igual forma, se analizaron los contenidos de las piezas periodísticas de los casos de estudio y se sistematizaron sus características, de acuerdo a los 
estándares del derecho humano de la libertad de expresión, contenidos en la Convención Americana de Derechos Humanos (OEA, 1969).

Se estudiaron también las resoluciones de los órganos reguladores encargados de aplicar las sanciones previstas en las leyes, sobre los casos de estudio. $Y$ se revisaron los contenidos de los reportes de organizaciones no gubernamentales que protegen la libertad de prensa sobre los casos escogidos (Fundamedios de Ecuador e Instituto Presa y Sociedad, IPYS, de Venezuela).

Estas dos organizaciones de periodistas fueron seleccionadas por cuanto son instituciones locales que están especializadas en el monitoreo de la situación de la libertad de expresión. Sus reportes son tomados como fuentes primarias de información por la Relatoría para la Libertad de Expresión y la Comisión Interamericana de Derechos Humanos, órganos de la OEA.

De forma específica se revisaron los efectos de la aplicación de los siguientes artículos de la LOC: 1) Artículo 24, referido al ejercicio del derecho a réplica. 2) Artículo 25, que establece que los medios de comunicación deben abstenerse de "de tomar posición institucional sobre la inocencia o culpabilidad de las personas que están involucradas en una investigación legal o proceso judicial penal"; y 3) Artículo 26, referido al concepto "linchamiento mediático", que prohíbe la difusión de contenidos que puedan "desprestigiar a una persona natural o jurídica o reducir su credibilidad pública" (Asamblea Nacional de Ecuador, 2013, s/p).

De igual forma, se examinaron las consecuencias que tuvo para la libertad de expresión la aplicación del artículo 27 de la Ley RESORTE, que incluye la prohibición de contenidos que: "Inciten o promuevan el odio y la intolerancia por razones religiosas, políticas, por diferencia de género, por racismo o xenofobia" y aquellos que "fomenten zozobra en la ciudadanía o alteren el orden público", entre otras prohibiciones (Asamblea Nacional de la República Bolivariana de Venezuela, 2011, s/p).

A efectos de delimitar el tema y lograr una mayor comprensión de los efectos de aplicación de los referidos preceptos legales, se tomaron como referencia los siguientes casos de Ecuador: 1) Resolución de la SUPERCOM que obliga a la televisora Teleamazonas a presentar una disculpa pública al presidente de la Federación Ecuatoriana de Fútbol (FEF), Luis Chiriboga, por presunta incursión en "linchamiento mediático", en 2015, por comentarios difundidos en el 


\section{Impacto de las leyes de comunicación de Ecuador y Venezuela en el}

ejercicio de la libertad de expresión, a partir de 6 casos emblemáticos

programa deportivo Dream Team. 2) Aplicación de una multa por $\$ 90$ mil al diario El Universo y orden de rectificación, por publicación de una caricatura de Xavier Bonilla, referida al allanamiento y confiscación de computadoras en la vivienda del periodista Fernando Villavicencio. 3) Resolución No. 038-2014INPS-DNJRD, de 2014, de la SUPERCOM, que impidió el ejercicio del derecho a réplica, establecido en el artículo 24 de la LOC, en el programa del presidente Correa, "Enlace Ciudadano".

De Venezuela se revisaron los siguientes casos: 1) La orden de la gubernamental Comisión Nacional de Telecomunicaciones (CONATEL), de sacar del aire a televisora colombiana NTN24, que transmitía su señal en Venezuela a través de los servicios de televisión por suscripción, luego de que el canal diera cobertura a hechos de violencia que se registraron en el país tras una manifestación estudiantil, el 12 febrero de 2014. 2) La apertura de un procedimiento administrativo sancionatorio contra la televisora privada Globovisión, que pudo ocasionar la salida del aire temporal o definitiva del canal, por la transmisión de un programa periodístico sobre la escasez de alimentos, que ha afectado a Venezuela durante el gobierno de Nicolás Maduro. 3) La salida del aire de los servicios de televisión por suscripción de la cadena internacional CNN en español, el 15 de febrero de 2017, luego de que emitiera un reportaje sobre presunta venta de pasaportes y cédulas de identidad venezolanos a personas de otras nacionalidades.

Si bien, los casos citados no son los únicos registrados por la aplicación de ambas leyes, constituyen ejemplos ilustrativos del impacto de estas legislaciones en el ejercicio de la libertad de expresión en Ecuador y Venezuela. La selección de los mismos se hizo a partir de las consecuencias que tuvieron para el ejercicio de la libertad de expresión, toda vez que incluyeron sanciones que podrían ser aplicadas a otros medios de comunicación.

\section{Hallazgos}

Contrastan, con las garantías establecidas en la LOC, un conjunto de prohibiciones que pueden derivar en censura o autocensura, entre ellas: multas que ocasionan lesiones económicas y afectan el funcionamiento de los medios de comunicación; y la figura de "linchamiento mediático" (artículo 26), cuya definición es ambigua y puede generar interpretaciones discrecionales, que ocasionen medidas de censura en los medios de comunicación.

En el caso de la Ley RESORTE, a pesar de que en su artículo 2 la ley establece como uno de sus principios la "prohibición de censura", el texto incurre 


\section{Impacto de las leyes de comunicación de Ecuador y Venezuela en el}

ejercicio de la libertad de expresión, a partir de 6 casos emblemáticos

en contradicción cuando en su artículo 27 establece la prohibición de contenidos que "fomenten zozobra en la ciudadanía" (Asamblea Nacional de la República Bolivariana de Venezuela, 2011), el cual resulta ambiguo y deja a criterio del órgano regulador su interpretación y la discrecionalidad en su aplicación. El término "zozobra" no está contemplado como una de las posibles limitaciones legítimas, dentro de los estándares internacionales del derecho a la libertad de expresión,

La ley venezolana contempla también la posibilidad de aplicar una medida cautelar, mediante la cual se prohíbe la difusión inmediata de contenidos (Asamblea Nacional de la República Bolivariana de Venezuela, 2011), sin esperar los lasos legales establecidos para que los medios de comunicación radioeléctricos o electrónicos puedan ejercer su derecho a la defensa (ver Cuadro N. ${ }^{\circ} 1$ ).

Partiendo de la metodología empleada, se presentan a continuación los hallazgos, los cuales fueron organizados en cinco cuadros en los que se muestran los siguientes aspectos de los casos estudiados: Las regulaciones (garantías, restricciones y prohibiciones) contempladas en las leyes estudiadas, que fueron aplicadas en los casos de estudio. También se presentan las características de las informaciones de los casos estudiados (tipo de publicación, abordaje de asuntos de interés público, referencia a autoridades públicas/gobierno). Se señala la presencia o ausencia de contenido tipificado como limitación legítima a la libertad de expresión. Se demuestra si el contenido de los casos de estudio respeta los estándares de libertad de expresión contenidos en la Convención Americana de Derechos Humanos.

De igual forma, se presenta la revisión que se hizo de las resoluciones de los casos por parte de las autoridades competentes y el impacto de la aplicación de las leyes en el derecho a la libertad de expresión. 
Cuadro N. ${ }^{\circ}$ 1. Regulaciones contempladas en la Ley Orgánica de Comunicación y en la Ley de Responsabilidad Social en Radio, Televisión y Medios Electrónicos

\begin{tabular}{|c|c|c|c|c|c|}
\hline País & Ley & Garantías & $\begin{array}{l}\text { Restricciones/ } \\
\text { prohibiciones }\end{array}$ & $\begin{array}{l}\text { Sujeto } \\
\text { aplicación }\end{array}$ & $\begin{array}{l}\text { Órganos } \\
\text { responsable } \\
\text { de la } \\
\text { aplicación }\end{array}$ \\
\hline Ecuador & $\begin{array}{l}\text { Ley Orgánica de } \\
\text { Comunicación } \\
\text { (2013) }\end{array}$ & 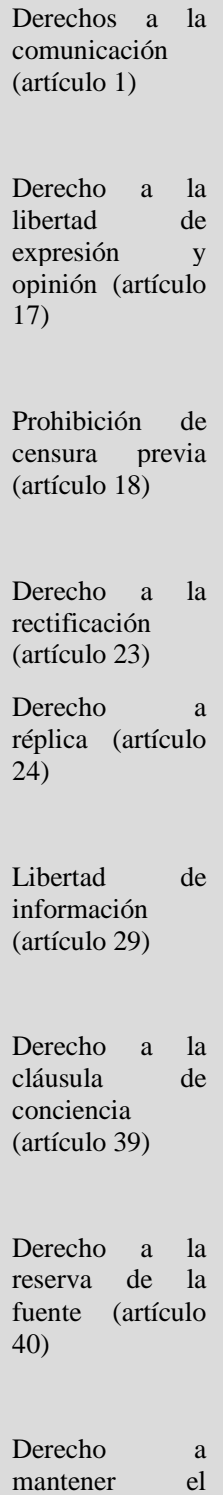 & 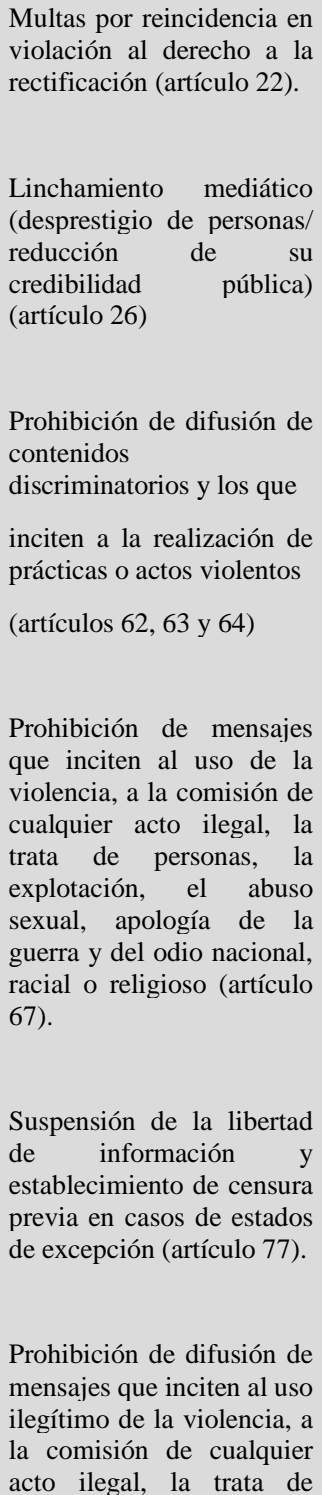 & $\begin{array}{l}\text { Radio, televisión, } \\
\text { medios impresos } \\
\text { (incluye contenidos } \\
\text { de medios de } \\
\text { comunicación } \\
\text { social replicados } \\
\text { por internet) } \\
\text { (artículo 5) }\end{array}$ & $\begin{array}{l}\text { Consejo de } \\
\text { Regulación y } \\
\text { Desarrollo de } \\
\text { la Información } \\
\text { y } \\
\text { Comunicación } \\
\\
\text { Superintenden } \\
\text { cia de la } \\
\text { Información y } \\
\text { Comunicación } \\
\text { (artículos } 55 \text { al } \\
59 \text { ) }\end{array}$ \\
\hline
\end{tabular}




\section{Luisa Torrealba Mesa}

Impacto de las leyes de comunicación de Ecuador y Venezuela en el ejercicio de la libertad de expresión, a partir de 6 casos emblemáticos

\begin{tabular}{|c|c|c|c|c|c|}
\hline & & $\begin{array}{l}\text { secreto } \\
\text { profesional } \\
\text { (artículo 41) } \\
\\
\text { Libre ejercicio } \\
\text { de la } \\
\text { comunicación } \\
\text { (artículo 42) }\end{array}$ & $\begin{array}{l}\text { personas, la explotación, el } \\
\text { abuso sexual, apología de } \\
\text { la guerra y del odio } \\
\text { nacional, racial o religioso. } \\
\text { El incumplimiento de } \\
\text { disposiciones del este } \\
\text { artículo podrá generar } \\
\text { sanciones administrativas } \\
\text { con una multa de } 1 \text { a } 5 \\
\text { salarios básicos. } \\
\text { (Artículo 67). }\end{array}$ & & \\
\hline Venezuela & $\begin{array}{l}\text { Ley de } \\
\text { Responsabilidad } \\
\text { Social en Radio, } \\
\text { Televisión y Medios } \\
\text { Electrónicos }\end{array}$ & 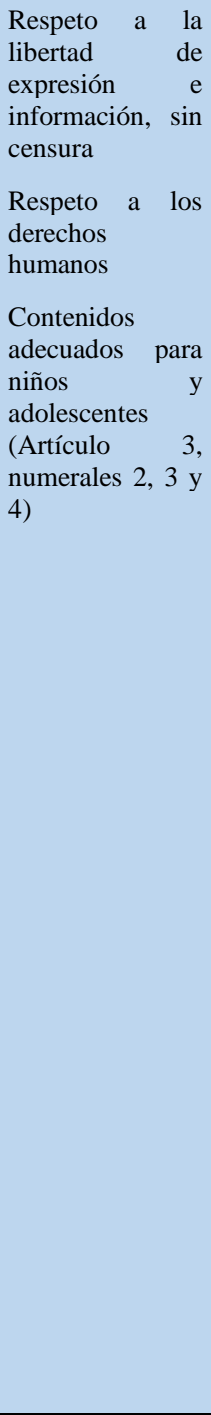 & 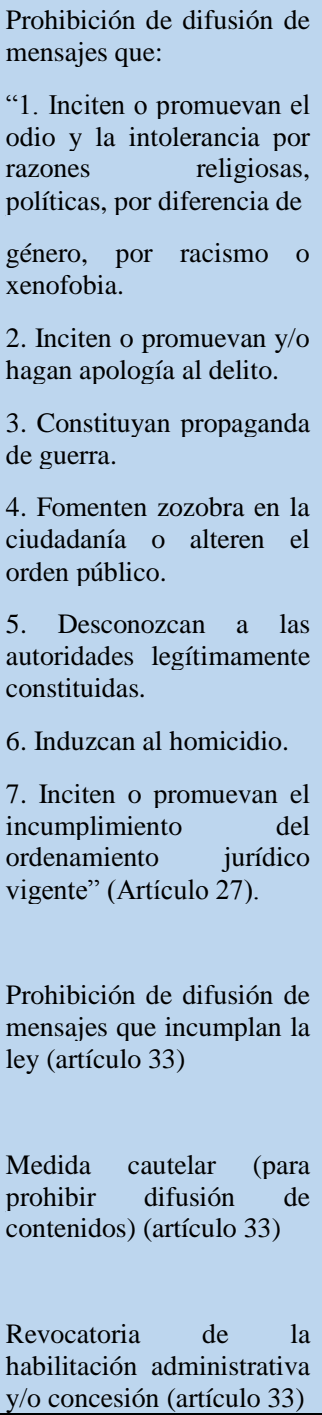 & $\begin{array}{l}\text { Radio, televisión y } \\
\text { medios } \\
\text { electrónicos } \\
\text { (contenidos) }\end{array}$ & $\begin{array}{l}\quad \text { Comisió } \\
\text { n Nacional de } \\
\text { Telecomunica } \\
\text { ciones } \\
\text { (CONATEL ) } \\
\\
\quad \text { Directori } \\
\text { o de } \\
\text { Responsabilid } \\
\text { ad Social en } \\
\text { Radio y } \\
\text { Televisión y }\end{array}$ \\
\hline
\end{tabular}


Fuente: Ley Orgánica de Comunicaciones (Ecuador), 2013, y Ley de Responsabilidad Social en Radio, Televisión y Medios Electrónicos (Venezuela), 2010.

Elaboración propia.

Se constató que estas leyes (la LOC y la RESORTE), que deberían promover el acceso y participación plural en los asuntos de la vida pública, han sido instrumentos coercitivos, debido a sus contradicciones conceptuales, la ambigüedad de algunos de sus conceptos y la dependencia de las autoridades de los organismos reguladores al poder ejecutivo, como se evidencia en sus artículos.

\section{Contenidos comunicacionales que fueron objeto de sanciones}

La revisión de los contenidos comunicacionales que fueron objeto $u$ ocasionaron la aplicación de sanciones fueron fundamentales para la consecución del objetivo de la investigación. La elección de los casos estuvo determinada por el impacto que tuvo en cada país.

De Ecuador, se revisaron las piezas comunicacionales correspondientes al programa Dream Team de Teleamazonas y se constató que en el mismo se incluyen contenidos informativos, junto a comentarios y análisis sobre el desempeño de los equipos de fútbol ecuatoriano, con chistes y parodias vinculados a dirigentes de ese sector deportivo.

En los segmentos de chistes incluían la participación de un muñeco tipo monigote identificado con el nombre de "El Ingeniero", que realizaba parodias del expresidente de la Federación Ecuatoriana de Fútbol (FEF), Luis Chiriboga, quien en la vida real es ingeniero y para el momento en que se registró el caso presidía la (FEF) (Dream Team, 2014a).

En estos espacios se emitieron comentarios supuestamente vinculados con actuaciones Chiriboga, pero sin mencionar su nombre. Todos los comentarios se realizaron en los segmentos de humor, sarcasmo y sátira y eran dirigidos todos al personaje "El Ingeniero", es decir se trataba de señalamientos indirectos con uso de la ironía (Dream Team, 2014b).

En cambio, en los segmentos en los que daban informaciones reales sobre el ámbito deportivo ecuatoriano, presentaron contenidos y comentarios incisivos, pero que no mostraban una intensión expresa de dañar la honra o reputación de Chiriboga. 


\section{Impacto de las leyes de comunicación de Ecuador y Venezuela en el} ejercicio de la libertad de expresión, a partir de 6 casos emblemáticos

En el mismo programa del 19 de octubre de 2014, cuando hicieron referencia a la reunión a la que asistió el dirigente del fútbol, uno de los conductores del programa que dio la información, señaló que a Chiriboga:

"nadie lo invitó, se fue a meter. Yo pregunto, ¿se fue a meter para ayudar a analizar mejoras, o para hacer proselitismo?". Ante lo que otro de los moderadores del programa respondió: "Yo pienso que, de una u otra manera, él tiene que ver la forma de buscar a aquellos que han sido solidarios con él en su momento, que han sido votos importantes para su permanencia en dicha institución y... bueno, aprovechó la coyuntura (...)" (Dream Team, 2014a). A pesar de la acuciosidad y el abordaje crítico en relación con el dirigente de fútbol, los comentarios $u$ opiniones no incurrieron de forma directa en descalificaciones que implicaran daños a los honra, como se aprecia en los extractos ilustrativos de los diálogos del programa, citados.

En el caso de la caricatura emitida por el diario El Universo, titulada "Regale Navidad" (NTN 24, 2014) de Xavier Bonilla, se retrató con imágenes la forma como presuntamente la policía y la fiscalía de Ecuador allanaron la casa del periodista Fernando Villavicencio, el 26 de diciembre de 2013. Aunque se desconoció el motivo del allanamiento, el afectado presumió que el hecho estuvo vinculado con denuncias que había hecho sobre casos de supuesta corrupción en el gobierno del entonces presidente ecuatoriano Correa.

La caricatura de Bonilla narró gráficamente cómo los funcionarios derribaron la puerta de la vivienda y cómo extrajeron algunos aparatos electrónicos y cajas con documentos de su vivienda. Las imágenes guardan coherencia con el titular que las acompaña: "Policía y Fiscalía allanan domicilio de Fernando Villavicencio y se llevan documentación de denuncias de corrupción" (NTN 24, 2014).

Al tratarse de una representación gráfica no pudo demostrar que los documentos sustraídos eran pruebas de denuncias de corrupción. Se constató también que Bonilla hizo uso de un recurso característico del género, como es la exageración de rasgos o acciones narradas, cuando mostró las botas de funcionarios policiales sobre la puerta, que yacía derribada en el piso, con una persona debajo.

En el caso del programa del entonces presidente Correa "Enlace Ciudadano N. ${ }^{\circ}$ 362", (Enlace Ciudadano, 2014b) transmitido el 22 de febrero de 2014, el mandatario hizo una mención del empresario y directivo de una empresa encuestadora, Blasco Peñaherrera, de 2 minutos y 2 segundos de 


\section{Impacto de las leyes de comunicación de Ecuador y Venezuela en el} ejercicio de la libertad de expresión, a partir de 6 casos emblemáticos duración, usando el término "fascista", para referirse a él y acusándolo de manipulador (ver video a partir de las 3 horas, 15 minutos y 58 segundos).

Debido a que Peñaherrera se sintió afectado por los señalamientos hechos por el mandatario, activó una solicitud del derecho a réplica, consagrado tanto en la Constitución de Ecuador, como en la LOC.

Cuando el presidente Correa llamó "fascista" al empresario, afectó su reputación, condición que es protegida en los estándares internacionales de la libertad de expresión incluidos en la Convención Americana de Derechos Humanos. No obstante, en el análisis que se realizó del caso se enfocó en la negativa del derecho a réplica, la cual constituyó una limitación para el ejercicio de la libertad de expresión por parte de Peñaherrera y marcó un precedente negativo para la exigencia de este derecho por parte de los ciudadanos.

En relación con Venezuela, los tres casos seleccionados tuvieron dos elementos comunes: fueron transmitidos por televisoras (dos internacionales y una nacional) y los contenidos difundidos correspondieron a la cobertura de hechos de interés público, que involucraron a organismos o actores gubernamentales. En ninguno de los casos se constató la inclusión de contenidos tipificados como limitaciones legítimas a la libertad de expresión.

El caso de la cadena colombiana NTN 24 (Venezuela Lucha, 2014), que transmitía su señal a través de los servicios de televisión por suscripción en Venezuela, se refirió a la cobertura que realizaron sobre una marcha y protesta estudiantil, realizada en Caracas, el 12 de febrero de 2014, que derivó en hechos de violencia y que dejó 3 personas fallecidas y varias heridas.

La cobertura se basó en transmisiones en vivo de la manifestación estudiantil y del ataque recibido por los estudiantes y manifestantes, por parte de miembros de cuerpos de inteligencia, de civiles armados y de la militar Guardia Nacional Bolivariana. Incluyó también videos sobre las respuestas de los afectados por las agresiones. También, emitieron entrevistas a analistas y dirigentes políticos y fotografías y mensajes enviados por la audiencia del canal a través de redes sociales.

En las imágenes se observaban: las barreras formadas por funcionarios de la militar Guardia Nacional Bolivariana, que portaban cascos y escudos y bloqueaban el avance de los manifestantes; cientos de personas que participaban en la manifestación convocada por la oposición; jóvenes manifestantes con sus rostros cubiertos; personas encapuchadas que 


\section{Impacto de las leyes de comunicación de Ecuador y Venezuela en el} ejercicio de la libertad de expresión, a partir de 6 casos emblemáticos atacaban de forma violenta la manifestación; guardias nacionales reprimiendo a manifestantes; y manifestantes heridos. La difusión de esas imágenes

resultó incómoda para el gobierno venezolano, quien optó por silenciarlas, a través de la decisión gubernamental que dejó fuera del aire al canal.

El caso Globovisión, televisora de señal abierta dedicada a la divulgación de información noticiosa, durante las 24 horas del día, se trató de la emisión del programa semanal "Caso de Investigación", en el que se abordó el tema de la escasez de alimentos que afectaba al país. A través de entrevistas a expertos, visitas a centros de venta de alimentos, estadísticas no oficiales y datos de organizaciones independientes lograron documentar el tema. En el programa mostraron testimonios de ciudadanos que relataron las dificultades para conseguir alimentos, repuestos y vehículos nuevos o usados. Tras el procedimiento administrativo iniciado en contra del canal, el programa "Caso de Investigación" fue sacado de la oferta de programación de Globovisión. El registro de la emisión en la que se abordó el tema de la escasez fue eliminado del archivo de la página web de la televisora http://globovision.com/.

Con respecto a CNN el producto comunicacional estudiado fue un reportaje de investigación periodística sobre la presunta venta de pasaportes venezolanos a ciudadanos de otras nacionalidades, que incluyen a personas con supuestos nexos terroristas, titulada "Pasaportes en la sombra" (CNN, 2017b). El trabajo mostró entrevistas con testigos en EE. UU., Reino Unido, España y Venezuela, documentos e informes oficiales y relató lo que hicieron para corroborar y contrastar parte de la información a la que tuvieron acceso. Mostró también videos de los intentos infructuosos que hicieron por obtener una versión oficial, por parte de la entonces canciller de Venezuela, Delcy Rodríguez, y la breve y vaga respuesta que lograron, luego de meses de intentos.

"Un reporte confidencial de inteligencia regional de 2013 obtenido por CNN dice que 173 individuos del Medio Oriente obtuvieron pasaportes y documentos venezolanos de 2008 a 2012. Entre ellos, personas vinculadas al grupo terrorista Hezbollah", afirmó el reportaje que puede ser consultado en la web de la cadena informativa, en el siguiente enlace http://cnnespanol.cnn.com/2017/02/06/pasaportes-venezolanos-en-manosequivocadas/ (CNN, 2017b).

"Según el informe, el hombre que ordenó la emisión de los pasaportes es Tareck El Aissami, un político venezolano que fue nombrado vicepresidente de la república en enero de este año" (CNN, 2017b), agregó el trabajo periodístico (ver Cuadro $N^{\circ} 2$ ). 
Cuadro $\mathbf{N}^{\circ}$ 2. Productos comunicacionales de los casos de estudio

\begin{tabular}{|c|c|c|c|c|c|c|c|c|}
\hline \multirow[t]{2}{*}{ País } & \multirow[t]{2}{*}{ Caso } & \multirow[t]{2}{*}{$\begin{array}{l}\text { Tipo de } \\
\text { publicació } \\
\text { n }\end{array}$} & \multicolumn{2}{|c|}{$\begin{array}{l}\text { Abor } \\
\text { da } \\
\text { asuntos } \\
\text { de } \\
\text { interés } \\
\text { público }\end{array}$} & \multicolumn{2}{|c|}{$\begin{array}{l}\text { Referen } \\
\text { cia a } \\
\text { autoridade } \\
\text { s públicas/ } \\
\text { gobierno }\end{array}$} & \multicolumn{2}{|c|}{$\begin{array}{l}\quad \text { Incluye } \\
\text { contenidos } \\
\text { tipificados } \\
\text { como } \\
\text { limitacione } \\
\text { s legítimas } \\
\text { a la libertao } \\
\text { de } \\
\text { expresión }\end{array}$} \\
\hline & & & Sí & No & sí & No & Sí & No \\
\hline \multirow[t]{3}{*}{ Ecuador } & Teleamazonas & Audiovisual & $\sqrt{ }$ & & & $\sqrt{ }$ & & $\sqrt{ }$ \\
\hline & $\begin{array}{c}\text { El } \\
\text { Universo }\end{array}$ & $\begin{array}{l}\text { Impresa- } \\
\text { Caricatura }\end{array}$ & $\sqrt{ }$ & & $\sqrt{ }$ & & & $\sqrt{ }$ \\
\hline & $\begin{array}{c}\text { Enlace } \\
\text { Ciudadano }\end{array}$ & Audiovisual & $\sqrt{ }$ & & $\sqrt{ }$ & & $\sqrt{ }$ & \\
\hline \multirow{3}{*}{$\begin{array}{l}\text { Venezuel } \\
\text { a }\end{array}$} & NTN 24 & Audiovisual & $\sqrt{ }$ & & $\sqrt{ }$ & & & $\sqrt{ }$ \\
\hline & Globovisión & Audiovisual & $\sqrt{ }$ & & $\sqrt{ }$ & & & $\sqrt{ }$ \\
\hline & CNN & Audiovisual & $\sqrt{ }$ & & $\sqrt{ }$ & & & $\sqrt{ }$ \\
\hline
\end{tabular}

Fuente: Elaboración propia.

En todos los productos comunicacionales de los casos estudiados se difundieron contenidos que referían a asuntos de interés público. El programa difundido por Teleamazonas se refirió a un alto dirigente del sector deportivo, el presidente de la Federación Ecuatoriana de Fútbol; en los demás estuvieron involucradas autoridades gubernamentales.

Puede verse una imagen con una captura fotográfica de la caricatura en el siguiente enlace: https://drive.google.com/file/d/0B8NHHuE83RFoN2VTRjgydTIKU0k/view?usp=sharing

Solo en uno de los casos, el identificado como Enlace Ciudadano (referido a contenidos emitidos en el programa televisivo del entonces presidente Correa), se emitió una acusación que constituye un contenido tipificado como limitación 
Impacto de las leyes de comunicación de Ecuador y Venezuela en el

ejercicio de la libertad de expresión, a partir de 6 casos emblemáticos

legítima a la libertad de expresión: la acusación de "fascista", que hizo el mandatario contra un empresario.

5. ESTÁNDARES PARA LA LIBERTAD DE EXPRESIÓN A PARTIR DE LOS CUALES SE HIZO EL ESTUDIO

Una de las variables que se consideró fue la presencia de contenido tipificado como limitaciones legítimas a la libertad de expresión. Para ello se hizo una revisión exhaustiva a partir de los límites para el derecho contemplados en el artículo 13 de la Convención Americana de Derechos Humanos (OEA, 1969).

En dos de los casos de Ecuador se constató que los productos comunicacionales no incluyeron de forma directa contenido tipificado como limitaciones legítimas a la libertad de expresión (Teleamazonas y El Universo); sin embargo, en el caso de Teleamazonas se emitieron algunas frases 0 comentarios en tono de humor y se hizo un muñeco tipo monigote inspirado en un particular, los cuales, de manera indirecta, pudieron afectar la honra y reputación de la persona.

En el hecho registrado en el programa televisivo presidencial Enlace Ciudadano, Correa acusó a Blasco Peñaherrera de ser un manipulador y lo llamó "fascista". Con este calificativo, el mandatario afectó la reputación del empresario, con lo cual vulneró uno de los estándares del derecho a la libertad de expresión protegido en la Convención Americana de Derechos Humanos.

En ninguno de los casos de Venezuela se constató la inclusión de contenidos tipificados como limitaciones legítimas a la libertad de expresión o contenidos que podrían derivar en responsabilidades ulteriores, según lo señalado en el artículo 13 de la Convención Americana de Derechos Humanos (ver cuadro N. ${ }^{\circ}$ $3)$. 
Luisa Torrealba Mesa

Impacto de las leyes de comunicación de Ecuador y Venezuela en el

ejercicio de la libertad de expresión, a partir de 6 casos emblemáticos

Cuadro $N .^{\circ}$ 3. Presencia de contenido tipificado como limitación legítima a la libertad de expresión

\begin{tabular}{|c|c|c|c|c|}
\hline País & Caso & $\begin{array}{l}\text { Limitación legítima a la libertad de } \\
\text { expresión }\end{array}$ & Sí & No \\
\hline \multirow[t]{10}{*}{ Ecuador } & \multirow[t]{10}{*}{ Teleamazonas } & Incluye propaganda de guerra & & $\sqrt{ }$ \\
\hline & & Hace apología al odio nacional & & $\sqrt{ }$ \\
\hline & & $\begin{array}{l}\text { Hace apología al odio por motivos } \\
\text { raciales }\end{array}$ & & $\sqrt{ }$ \\
\hline & & $\begin{array}{l}\text { Hace apología al odio por motivos } \\
\text { religiosos }\end{array}$ & & $\sqrt{ }$ \\
\hline & & $\begin{array}{l}\text { Auspicia el odio por motivo de } \\
\text { nacionalidad }\end{array}$ & & $\sqrt{ }$ \\
\hline & & $\begin{array}{l}\text { Propicia divulgación de información } \\
\text { que ponga } \\
\text { en riesgo la seguridad nacional }\end{array}$ & & $\sqrt{ }$ \\
\hline & & $\begin{array}{l}\text { Propicia divulgación de información } \\
\text { que ponga } \\
\text { en riesgo el orden público }\end{array}$ & & $\sqrt{ }$ \\
\hline & & $\begin{array}{l}\text { Propicia divulgación de información } \\
\text { que ponga } \\
\text { en riesgo la salud pública }\end{array}$ & & $\sqrt{ }$ \\
\hline & & $\begin{array}{l}\text { Propicia divulgación de información } \\
\text { que ponga } \\
\text { en riesgo la moral pública }\end{array}$ & & $\sqrt{ }$ \\
\hline & & $\begin{array}{l}\text { Propicia divulgación de información } \\
\text { que ponga } \\
\text { en riesgo la dignidad, honra o } \\
\text { reputación de } \\
\text { particulares }\end{array}$ & & $\sqrt{ }$ \\
\hline
\end{tabular}

El 10 de septiembre de 2012, el gobierno venezolano "denunció" formalmente la Convención Americana sobre Derechos Humanos. El trámite implica que las violaciones a derechos humanos que se hayan registrado después del 10 de septiembre de 2013, en el país, no podrán ser conocidas por la Corte Interamericana de Derechos Humanos (CortelDH). Sin embargo, no afecta la acción de la Comisión Interamericana de Derechos 


\section{Luisa Torrealba Mesa}

Impacto de las leyes de comunicación de Ecuador y Venezuela en el

ejercicio de la libertad de expresión, a partir de 6 casos emblemáticos

Humanos, por cuanto Venezuela sigue siendo parte de la OEA. Por otro lado, la denuncia hecha por el Estado venezolano contra la Convención contraviene el artículo 23 de la Constitución venezolana que le da rango constitucional a pactos y tratados internacionales de derechos humanos; por lo que, de cara a esta investigación, apelamos a la vigencia de la Convención Americana sobre Derechos Humanos en Venezuela, según lo establecido en la Constitución del país (Asamblea Nacional de la República Bolivariana de Venezuela, $2009, s / p)$.

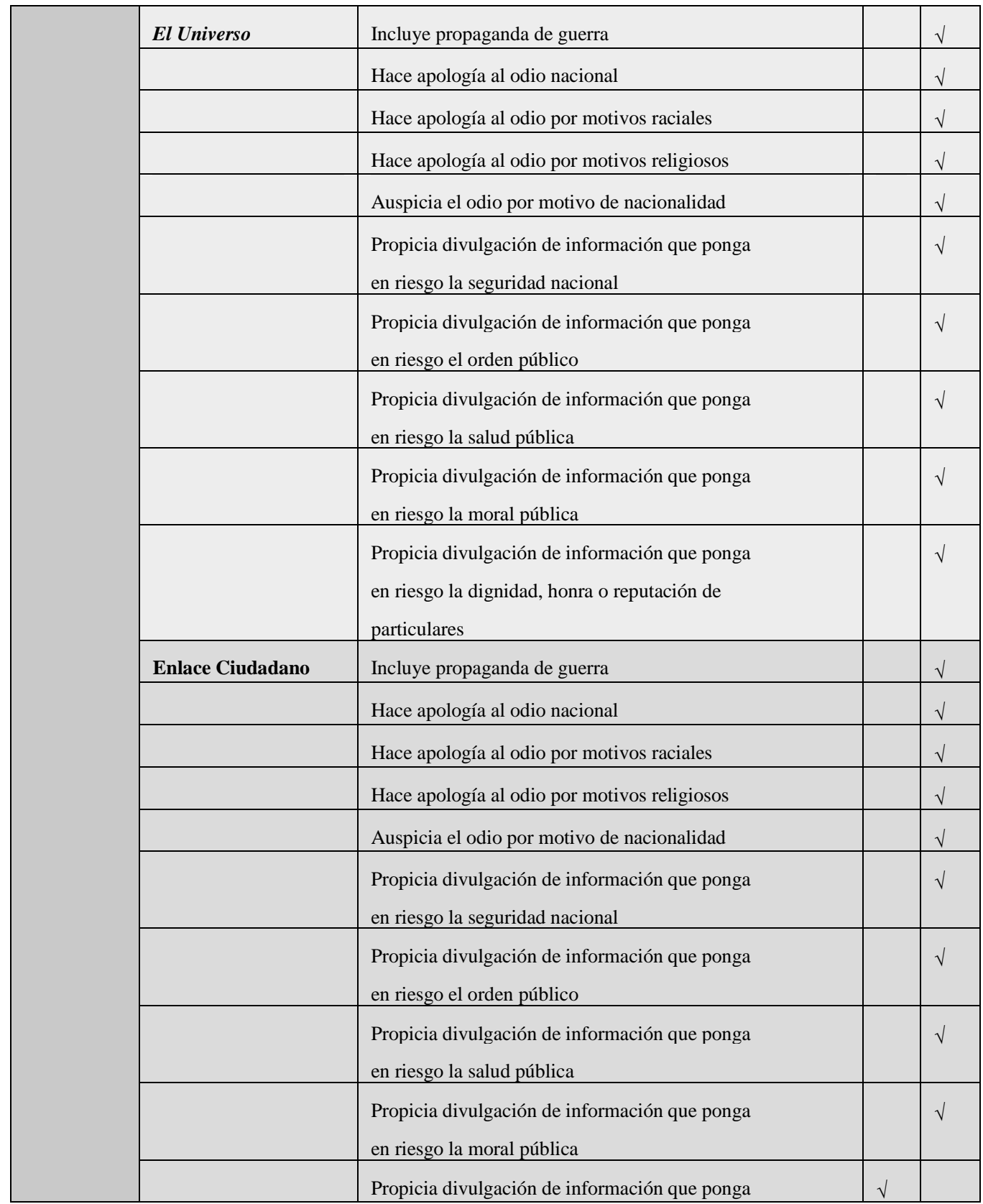




\section{Luisa Torrealba Mesa}

Impacto de las leyes de comunicación de Ecuador y Venezuela en el ejercicio de la libertad de expresión, a partir de 6 casos emblemáticos

\begin{tabular}{|c|c|c|c|}
\hline & & $\begin{array}{l}\text { en riesgo la dignidad, honra o reputación de } \\
\text { particulares }\end{array}$ & \\
\hline \multirow[t]{21}{*}{ Venezuela } & NTN 24 & Incluye propaganda de guerra & $\sqrt{ }$ \\
\hline & & Hace apología al odio nacional & $\sqrt{ }$ \\
\hline & & Hace apología al odio por motivos raciales & $\sqrt{ }$ \\
\hline & & Hace apología al odio por motivos religiosos & $\sqrt{ }$ \\
\hline & & Auspicia el odio por motivo de nacionalidad & $\sqrt{ }$ \\
\hline & & $\begin{array}{l}\text { Propicia divulgación de información que ponga } \\
\text { en riesgo la seguridad nacional }\end{array}$ & $\sqrt{ }$ \\
\hline & & $\begin{array}{l}\text { Propicia divulgación de información que ponga } \\
\text { en riesgo el orden público }\end{array}$ & $\sqrt{ }$ \\
\hline & & $\begin{array}{l}\text { Propicia divulgación de información que ponga } \\
\text { en riesgo la salud pública }\end{array}$ & $\sqrt{ }$ \\
\hline & & $\begin{array}{l}\text { Propicia divulgación de información que ponga } \\
\text { en riesgo la moral pública }\end{array}$ & $\sqrt{ }$ \\
\hline & & $\begin{array}{l}\text { Propicia divulgación de información que ponga } \\
\text { en riesgo la dignidad, honra o reputación de } \\
\text { particulares }\end{array}$ & $\sqrt{ }$ \\
\hline & Globovisión & Incluye propaganda de guerra & $\sqrt{ }$ \\
\hline & & Hace apología al odio nacional & $\sqrt{ }$ \\
\hline & & Hace apología al odio por motivos raciales & $\sqrt{ }$ \\
\hline & & Hace apología al odio por motivos religiosos & $\sqrt{ }$ \\
\hline & & Auspicia el odio por motivo de nacionalidad & $\sqrt{ }$ \\
\hline & & $\begin{array}{l}\text { Propicia divulgación de información que ponga } \\
\text { en riesgo la seguridad nacional }\end{array}$ & $\sqrt{ }$ \\
\hline & & $\begin{array}{l}\text { Propicia divulgación de información que ponga } \\
\text { en riesgo el orden público }\end{array}$ & $\sqrt{ }$ \\
\hline & & $\begin{array}{l}\text { Propicia divulgación de información que ponga } \\
\text { en riesgo la salud pública }\end{array}$ & $\sqrt{ }$ \\
\hline & & $\begin{array}{l}\text { Propicia divulgación de información que ponga } \\
\text { en riesgo la moral pública }\end{array}$ & $\sqrt{ }$ \\
\hline & & $\begin{array}{l}\text { Propicia divulgación de información que ponga } \\
\text { en riesgo la dignidad, honra o reputación de } \\
\text { particulares }\end{array}$ & $\sqrt{ }$ \\
\hline & CNN & Incluye propaganda de guerra & $\sqrt{ }$ \\
\hline
\end{tabular}


Luisa Torrealba Mesa

Impacto de las leyes de comunicación de Ecuador y Venezuela en el ejercicio de la libertad de expresión, a partir de 6 casos emblemáticos

\begin{tabular}{|c|c|c|c|}
\hline & & Hace apología al odio nacional & $\sqrt{ }$ \\
\hline & & Hace apología al odio por motivos raciales & $\sqrt{ }$ \\
\hline & & Hace apología al odio por motivos religiosos & $\sqrt{ }$ \\
\hline & & Auspicia el odio por motivo de nacionalidad & $\sqrt{ }$ \\
\hline & & $\begin{array}{l}\text { Propicia divulgación de información que ponga } \\
\text { en riesgo la seguridad nacional }\end{array}$ & $\sqrt{ }$ \\
\hline & & $\begin{array}{l}\text { Propicia divulgación de información que ponga } \\
\text { en riesgo el orden público }\end{array}$ & $\sqrt{ }$ \\
\hline & & $\begin{array}{l}\text { Propicia divulgación de información que ponga } \\
\text { en riesgo la salud pública }\end{array}$ & $\sqrt{ }$ \\
\hline & & $\begin{array}{l}\text { Propicia divulgación de información que ponga } \\
\text { en riesgo la moral pública }\end{array}$ & $\sqrt{ }$ \\
\hline & & $\begin{array}{l}\text { Propicia divulgación de información que ponga } \\
\text { en riesgo la dignidad, honra o reputación de } \\
\text { particulares }\end{array}$ & $\sqrt{ }$ \\
\hline
\end{tabular}

Fuente: Elaboración propia

La acusación de "fascista", que hizo el entonces expresidente Correa constituye un tipo de contenido que puso en riesgo la dignidad, honra 0 reputación de un particular y está reconocido entre las posibles limitaciones legítimas a la libertad de expresión, de acuerdo a los instrumentos internacionales de derechos humanos.

Como evidencia el cuadro, en el resto de los casos no se encontraron contenidos que pudieran ser calificados dentro de las limitaciones a la libre expresión, contempladas en los instrumentos internacionales de derechos humanos.

\section{La posición de las organizaciones locales que defienden la libertad de expresión}

Otra variable que se consideró en el análisis de los casos fue el de las limitaciones a la libertad de expresión, vistas a partir de los reportes realizados por organizaciones no gubernamentales expertas en el monitoreo del derecho: Fundamedios, de Ecuador, e Instituto Prensa y Sociedad (IPYS), de Venezuela.

En los casos correspondientes a Ecuador se constató que en los tres, las limitaciones a la libertad de expresión corresponden a "Sanciones por Ley Comunicación", de acuerdo a la clasificación hecha por Fundamedios, a partir 


\section{Impacto de las leyes de comunicación de Ecuador y Venezuela en el}

ejercicio de la libertad de expresión, a partir de 6 casos emblemáticos

del sistema de categorías, que emplea la organización, para el monitoreo de la situación de la libertad de expresión (Fundamedios, 2017).

Al reportar los casos, la organización explicó las violaciones a la libertad de expresión que identificó en cada uno, que consideran se sustentan en la aplicación de la Ley. En el caso Teleamazonas, el responsable de solicitar la acción que derivó en una sanción fue un particular: Luis Chiriboga, expresidente de FEF. Como consecuencia de la acción ejercida por él, la televisora fue obligada a difundir una disculpa pública, sobre la base del artículo 26 de la Ley Orgánica de Comunicación, (numerales 1 y 2) (Fundamedios, 2015).

En el caso del diario El Universo el responsable de la aplicación de la sanción fue la SUPERCOM, sin embargo, el presidente Correa tuvo responsabilidad indirecta, toda vez que en su programa "Enlace Ciudadano" $\mathrm{N}^{\circ}$ 355 (Enlace Ciudadano 2014a) acusó al caricaturista de ser un "sicario de tinta y enfermo" y amenazó con aplicarle la Ley de Comunicación por la referida caricatura.

El diario El Universo recibió una multa equivalente al $2 \%$ de su facturación promediada, de los tres meses anteriores a la aplicación de la sanción (USD 90 mil dólares). Y fue obligado a presentar una rectificación del texto que acompañó a la caricatura, en un periodo de 72 horas (Fundamedios, 2014a).

En el caso del espacio "Enlace Ciudadano", la SUPERCOM estableció que los programas televisivos del expresidente Correa "no constituyen contenido comunicacional que se encuentre regulado por la Ley Orgánica de Comunicación", y le fue negado el derecho a réplica que había solicitado el empresario Blasco Peñaherrera Solah (director de la encuestadora Market y presidente de la Cámara de Comercio de Quito) (Fundamedios, 2014b).

En los casos de Venezuela, la documentación que hizo el Instituto Prensa y Sociedad (IPYS) resaltó la presencia de patrones de censura en las decisiones que llevaron a la salida del aire de las cadenas internacionales NTN $24^{3}$ (IPYS Venezuela, 2014a) y CNN en Español ${ }^{4}$ (IPYS Venezuela, 2017). En ambos casos hubo órdenes directas del presidente de la República, Nicolás Maduro, de sacarlas del aire, las cuales fueron difundidas en alocuciones televisadas (IPYS Venezuela, 2014b).

En el caso de la televisora Globovisión, la medida tomada derivó en un patrón de censura y autocensura, que llevó al canal a sacar de su programación

\footnotetext{
${ }^{3}$ La señal de NTN 24 fue dejada de emitir en los servicios de televisión por suscripción de Venezuela, el 13 de febrero de 2014.

4 La señal de CNN en Español fue dejada de emitir en los servicios de televisión por suscripción de Venezuela desde el 15 de febrero de 2017.
} 


\section{Luisa Torrealba Mesa}

Impacto de las leyes de comunicación de Ecuador y Venezuela en el

ejercicio de la libertad de expresión, a partir de 6 casos emblemáticos el programa por el cual se generó la investigación (IPYS Venezuela, 2013) (ver Cuadro N. ${ }^{\circ}$ ).

Cuadro N. ${ }^{\circ}$ 4. Limitaciones a la libertad de expresión, de acuerdo a los reportes de organizaciones no gubernamentales locales sobre los casos

\begin{tabular}{|c|c|c|c|c|c|}
\hline País & Caso & $\begin{array}{l}\quad \text { Está } \\
\text { ndar de } \\
\text { libertad } \\
\text { de } \\
\text { expresi } \\
\text { ón } \\
\text { afectad } \\
\text { o }\end{array}$ & $\begin{array}{l}\text { Tipo de } \\
\text { violación a } \\
\text { la libre } \\
\text { expresión }\end{array}$ & $\begin{array}{l}\text { Responsab } \\
\text { le de la } \\
\text { aplicación de } \\
\text { la sanción }\end{array}$ & $\begin{array}{l}\text { Consec } \\
\text { uencias }\end{array}$ \\
\hline \multirow[t]{3}{*}{$\begin{array}{l}\text { Ecu } \\
\text { ador }\end{array}$} & $\begin{array}{l}\text { Teleamazo } \\
\text { nas }\end{array}$ & $\begin{array}{l}\text { Prohibici } \\
\text { ón de } \\
\text { censura }\end{array}$ & $\begin{array}{l}\text { "Sancio } \\
\text { nes por Ley } \\
\text { Comunicaci } \\
\text { ón" } \\
\quad \text { (Funda } \\
\text { medios) }\end{array}$ & 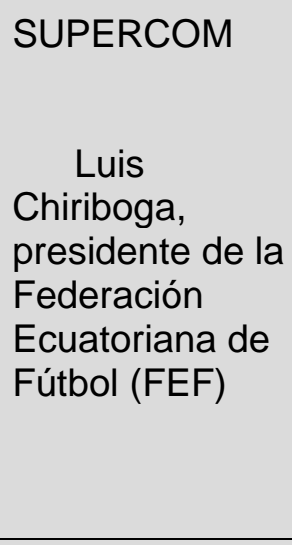 & $\begin{array}{l}\quad \text { Obligaci } \\
\text { ón de } \\
\text { difundir } \\
\text { disculpa } \\
\text { pública } \\
\text { (artículo } 26 \\
\text { de la Ley } \\
\text { Orgánica de } \\
\text { Comunicaci } \\
\text { ón, } \\
\text { numerales } 1 \\
\text { y 2) }\end{array}$ \\
\hline & $\begin{array}{c}\text { El } \\
\text { Universo }\end{array}$ & $\begin{array}{l}\quad \text { Liber } \\
\text { tad de } \\
\text { opinión }\end{array}$ & $\begin{array}{l}\text { "Sancio } \\
\text { nes por Ley } \\
\text { Comunicaci } \\
\text { ón" } \\
\quad \text { (Funda } \\
\text { medios) }\end{array}$ & $\begin{array}{l}\text { SUPERCO } \\
\text { M presidente } \\
\text { Correa }\end{array}$ & $\begin{array}{l}\quad \text { Multa al } \\
\text { diario El } \\
\text { Universo, } \\
\text { equivalente } \\
\text { al } 2 \% \text { de su } \\
\text { facturación } \\
\text { promediada } \\
\text { de los tres } \\
\text { meses } \\
\text { previos a la } \\
\text { aplicación } \\
\text { de la } \\
\text { sanción } \\
\text { (USD } 90 \text { mil } \\
\text { dólares) }\end{array}$ \\
\hline & & & & & Rectifica \\
\hline
\end{tabular}




\begin{tabular}{|c|c|c|c|c|}
\hline & & & & $\begin{array}{l}\text { ción, en } 72 \\
\text { horas, del } \\
\text { texto que } \\
\text { acompaña a } \\
\text { la caricatura }\end{array}$ \\
\hline $\begin{array}{r}\text { Enlace } \\
\text { Ciudadano }\end{array}$ & $\begin{array}{l}\quad \text { Restr } \\
\text { icción } \\
\text { del } \\
\text { derecho } \\
\text { a réplica }\end{array}$ & $\begin{array}{l}\text { "Sancio } \\
\text { nes por Ley } \\
\text { Comunicaci } \\
\text { ón" } \\
\quad \text { (Funda } \\
\text { medios) }\end{array}$ & SUPERCOM & \begin{tabular}{l}
\multicolumn{1}{c}{ Se } \\
estableció \\
que los \\
programas \\
televisivo del \\
presidente \\
Rafael \\
Correa \\
"Enlace \\
Ciudadano" \\
"no \\
constituyen \\
contenido \\
comunicacio \\
nal que se \\
encuentre \\
regulado por \\
la Ley \\
Orgánica de \\
Comunicaci \\
ón"
\end{tabular} \\
\hline & & & & $\begin{array}{l}\quad \text { Le fue } \\
\text { negado el } \\
\text { derecho a } \\
\text { réplica a } \\
\text { Blasco } \\
\text { Peñaherrera } \\
\text { Solah } \\
\text { (director de } \\
\text { la } \\
\text { encuestador } \\
\text { a Market y } \\
\text { presidente } \\
\text { de la } \\
\text { Cámara de } \\
\text { Comercio de } \\
\text { Quito). }\end{array}$ \\
\hline
\end{tabular}




\begin{tabular}{|c|c|c|c|c|c|}
\hline & & & & & $\begin{array}{l}\quad \text { Se violó } \\
\text { el derecho a } \\
\text { réplica } \\
\text { establecido } \\
\text { en el artículo } \\
66 \text { de la } \\
\text { Constitución } \\
\text { Nacional de } \\
\text { Ecuador y } \\
\text { en el artículo } \\
24 \text { de la } \\
\text { LOC. }\end{array}$ \\
\hline \multirow[t]{3}{*}{$\begin{array}{r}\text { Ven } \\
\text { ezuela }\end{array}$} & NTN 24 & $\begin{array}{l}\text { Prohi } \\
\text { bición de } \\
\text { censura }\end{array}$ & Censura & $\begin{array}{l}\quad \text { Presidente } \\
\text { de la República } \\
\text { Nicolás Maduro } \\
\\
\quad \text { Comisión } \\
\text { Nacional de } \\
\text { Telecomunicaci } \\
\text { ones } \\
\text { (CONATEL ) }\end{array}$ & $\begin{array}{l}\quad \text { Salida } \\
\text { del aire de } \\
\text { las parrillas } \\
\text { de las } \\
\text { empresas } \\
\text { de televisión } \\
\text { por } \\
\text { suscripción } \\
\text { de } \\
\text { Venezuela. }\end{array}$ \\
\hline & & & & & $\begin{array}{l}\quad \text { Fue } \\
\text { bloqueado el } \\
\text { acceso al } \\
\text { sitio web del } \\
\text { canal en } \\
\text { Venezuela }\end{array}$ \\
\hline & $\begin{array}{l}\text { Globovi } \\
\text { sión }\end{array}$ & $\begin{array}{l}\quad \text { Prohi } \\
\text { bición de } \\
\text { censura } \\
\quad \text { Dere } \\
\text { cho a la } \\
\text { informaci } \\
\text { ón }\end{array}$ & $\begin{array}{l}\text { Censura / } \\
\text { Autocensur } \\
\text { a }\end{array}$ & \begin{tabular}{l}
\multicolumn{1}{c}{ Comisión } \\
Nacional de \\
Telecomunicaci \\
ones \\
(CONATEL )
\end{tabular} & $\begin{array}{l}\quad \text { La } \\
\text { televisora } \\
\text { Globovisión } \\
\text { sacó del aire } \\
\text { el programa } \\
\text { Caso de } \\
\text { Investigació } \\
\text { n, en que } \\
\text { supuestame } \\
\text { nte se } \\
\text { emitieron los }\end{array}$ \\
\hline
\end{tabular}




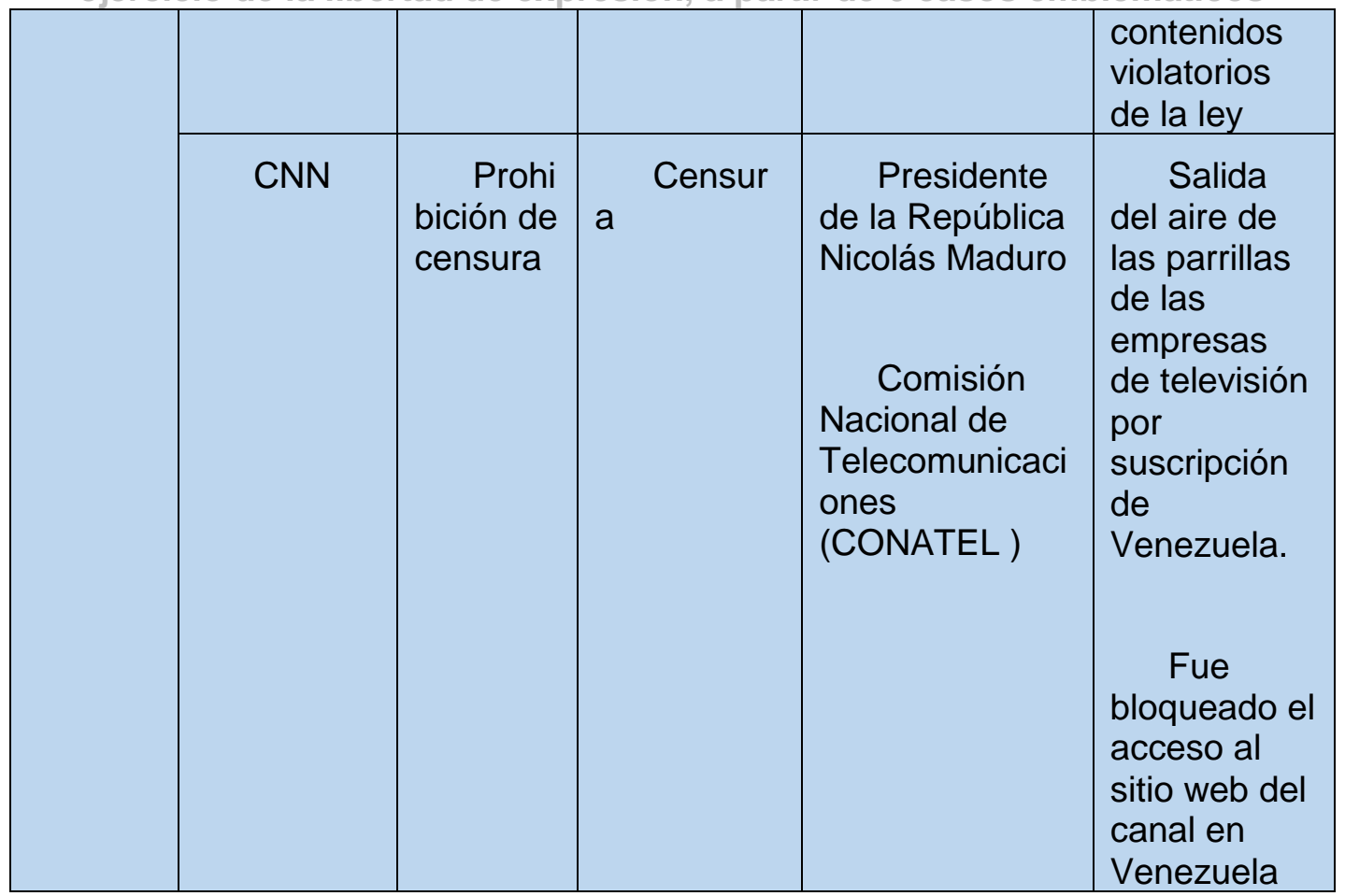

Fuente: Elaboración propia

Ambas organizaciones (Fundamedios de Ecuador e IPYS Venezuela) monitorean, de forma sistemática y permanente, el ejercicio de la libertad de expresión, a partir de un sistema de categorías, que definen distintos tipos de violaciones a la libertad de expresión, sustentados en las garantías para el derecho, contenidas en los instrumentos internacionales de derechos humanos.

\section{Argumentos esgrimidos por las autoridades encargadas de aplicar las leyes}

Se verificó si en cada uno de los casos estudiados hubo una investigación o procedimiento administrativo previo, que permitiera a los afectados ejercer el derecho a la defensa. Se corroboró que sí la hubo en los casos Teleamazonas (SUPERCOM, 2015) y El Universo (SUPERCOM, 2014a), de Ecuador; y en los de Globovisión (Conatel, 2013) y CNN (CONATEL, 2017).

Sin embargo, en el caso CNN (CONATEL, 2017) el procedimiento vino acompañado de una medida cautelar, que vulneró el derecho a la defensa, al 


\section{Impacto de las leyes de comunicación de Ecuador y Venezuela en el}

ejercicio de la libertad de expresión, a partir de 6 casos emblemáticos

ordenar a las empresas de televisión por suscripción del país, sacar del aire de forma inmediata el canal.

En el caso del programa presidencial "Enlace Ciudadano" (SUPERCOM, 2014b), la solicitud formulada por Blasco Peñaherrera ante la SUPERCOM no fue admitida y la decisión fue informada a través de una notificación razonada.

En el caso del canal NTN 24, la decisión de sacar del aire su señal de la oferta de las empresas de televisión por suscripción no pasó por una investigación previa. La decisión de la CONATEL se produjo por una orden directa del presidente de la República.

"Hay una gran manipulación en el mundo. Una televisora, que pretendió ser la competencia de Telesur y es el fracaso más grande que ha habido, llamada NTN 24, pretendía ayer, en cableras venezolanas, trasmitir la zozobra de un golpe de Estado (...)", dijo el presidente Maduro, en una alocución televisada, transmitida el 13 de abril de 2014. Seguidamente admitió su responsabilidad en la orden de sacar del aire el canal: "Fuera del aire NTN 24. Fue una decisión de Estado, para que lo sepan" (Noticias Venezuela, 2014, s/n). Así dejó claro el mandatario que no hubo un respeto de los parámetros legales, ni del derecho a la defensa. Que se trató de una decisión con una motivación política de silenciar a un medio, por transmitir contenidos considerados críticos por el gobierno nacional.

En los casos de Enlace Ciudadano (Enlace Ciudadano, 2014b), Globovisión, NTN 24 (Noticias Venezuela, 2014) y CNN (CONATEL, 2017) las decisiones de los organismos competentes implicaron prohibiciones expresas de difusión de contenidos.

En el programa presidencial ecuatoriano, se prohibió a un ciudadano el ejercicio del derecho a réplica. Al canal Globovisión se le prohibió informar sobre temas vinculados a la crisis de escasez de alimentos existente en el país (CONATEL, 2013). En cuanto a NTN 24 (CONATEL, 2014) y CNN (CONATEL, 2017) las decisiones implicaron que cesaran en Venezuela las transmisiones de ambas cadenas televisivas.

En los casos Teleamazonas (SUPERCOM, 2015) y El Universo (SUPERCOM, 2014a), no hubo medidas expresas de censura. En el primero se exigió una disculpa pública y en el segundo hubo una exigencia de rectificación.

Sobre la justificación legal de los casos, el de Teleamazonas (SUPERCOM, 2015) se sustentó en el artículo 26 de la LOC referido a "linchamiento mediático". El de El Universo (SUPERCOM, 2014a) se basó en el artículo 25 de la LOC, que prohíbe a los medios fijar posición sobre asuntos judiciales y el artículo 23 sobre el "derecho a rectificación". 


\section{Impacto de las leyes de comunicación de Ecuador y Venezuela en el}

ejercicio de la libertad de expresión, a partir de 6 casos emblemáticos

En relación con el espacio "Enlace Ciudadano" (SUPERCOM, 2014b), la decisión se sustentó en el artículo 5 de la LOC, según el cual el programa presidencial no se está comprendido dentro de los contenidos de medios de comunicación social, al considerarlo un espacio de rendición de cuentas por parte del jefe del gobierno.

Los casos de NTN 24 y Globovisión (CONATEL, 2013) tuvieron como base legal el artículo 27 de la Ley RESORTE, que prohíbe la difusión de contenidos que generen "zozobra" en la población. Mientras que el caso de CNN (CONATEL, 2017) mencionan la ley, sin citar ningún artículo en particular.

CONATEL inició el procedimiento contra Globovisión, de oficio, a partir del monitoreo realizado por el propio organismo a la televisora. El procedimiento como tal no contempló medidas de censura directa, sin embargo dejó sentada la posibilidad de multar al medio con un monto equivalente al $10 \%$ de los ingresos brutos correspondientes al ejercicio fiscal del año anterior, según lo establecido en el artículo 29 de la Ley de Responsabilidad Social en Radio, Televisión y Medios Electrónicos (Asamblea Nacional de la República Bolivariana de Venezuela, 2011), en caso de corroborarse la presunta violación de la Ley.

En el caso El Universo la SUPERCOM actuó de oficio ante la solicitud que hizo el presidente Rafael Correa, en su programa televisión "Enlace Ciudadano" (Enlace Ciudadano 2014a). No hubo una denuncia formal.

Sobre el programa Enlace Ciudadano (Enlace Ciudadano, 2014b), la decisión consistió en "inadmitir" el trámite y "archivar la petición del señor Blasco Peñaherrera" por considerar que "los pronunciamientos emitidos por el presidente de la República en los denominados "enlaces ciudadanos" no constituyen contenido comunicacional que se encuentre regulado en la Ley Orgánica de Comunicación" (SUPERCOM, 2014b, p. 4) (Ver Cuadro N.ํ5).

Cuadro N. ${ }^{\circ}$ 5. Resoluciones de los casos por parte de las autoridades competentes

\begin{tabular}{|c|c|c|c|c|c|c|c|}
\hline País & Caso & $\begin{array}{l}\quad \text { Inves } \\
\text { ción } \\
\text { procedin } \\
\text { to } \\
\text { administ } \\
\text { vo previd }\end{array}$ & $\begin{array}{l}\quad \text { Resolt } \\
\text { nes/ } \\
\text { expedient } \\
\text { del órg } \\
\text { regulador }\end{array}$ & \begin{tabular}{l}
\multicolumn{1}{r}{ Person } \\
stitución \\
solicitó \\
procedimie
\end{tabular} & $\begin{array}{r}\text { Organ } \\
\text { o que ar } \\
\text { la sanció }\end{array}$ & $\begin{array}{l}\text { Proh } \\
\text { ión exp } \\
\text { de difu } \\
\text { de } \\
\text { conteni }\end{array}$ & $\begin{array}{l}\text { Basa } \\
\text { nto lega } \\
\text { la medid }\end{array}$ \\
\hline $\begin{array}{l}\text { Ec } \\
\text { uador }\end{array}$ & $\begin{array}{l}\text { Tel } \\
\text { eamaz } \\
\text { onas }\end{array}$ & Sí & $\begin{array}{l}\frac{\frac{R E S}{\mathrm{OLUSO}}}{\mathrm{N} \mathrm{N}^{\circ}} \\
\frac{010-}{2015-} \\
\underline{\text { DNJRD- }}\end{array}$ & \begin{tabular}{l}
\multicolumn{1}{c}{ Luis } \\
Gustavo \\
Chiriboga \\
Acosta, \\
president \\
e de la
\end{tabular} & $\begin{array}{l}\quad \text { Supe } \\
\text { rintende } \\
\text { ncia de } \\
\text { la } \\
\text { Informac } \\
\text { ión y }\end{array}$ & No & $\begin{array}{l}\quad \text { "Lin } \\
\text { chamie } \\
\text { nto } \\
\text { mediáti } \\
\text { co" } \\
\text { (artícul }\end{array}$ \\
\hline
\end{tabular}


Luisa Torrealba Mesa

Impacto de las leyes de comunicación de Ecuador y Venezuela en el ejercicio de la libertad de expresión, a partir de 6 casos emblemáticos

\begin{tabular}{|c|c|c|c|c|c|c|}
\hline & & INPS & $\begin{array}{l}\text { Federació } \\
\mathrm{n} \\
\text { Ecuatoria } \\
\text { na de } \\
\text { Fúltbol }\end{array}$ & $\begin{array}{l}\text { Comunic } \\
\text { ación } \\
\text { (SUPER } \\
\text { COM) }\end{array}$ & & $\begin{array}{l}\text { o } 26 \text { de } \\
\text { la Ley } \\
\text { Orgánic } \\
\text { a de } \\
\text { Comuni } \\
\text { cación) }\end{array}$ \\
\hline $\begin{array}{l}\text { El } \\
\text { Univer } \\
\text { so }\end{array}$ & Sí & 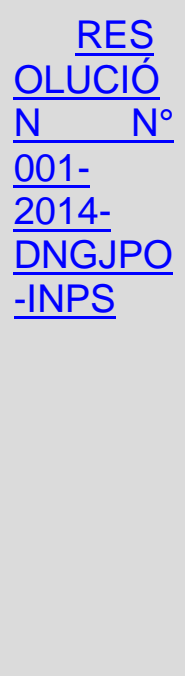 & 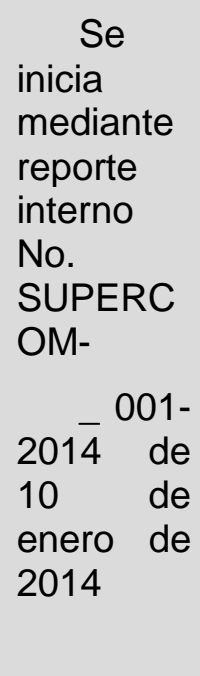 & $\begin{array}{l}\quad \text { Supe } \\
\text { rintende } \\
\text { ncia de } \\
\text { la } \\
\text { Informac } \\
\text { ión y } \\
\text { Comunic } \\
\text { ación } \\
\text { (SUPER } \\
\text { COM) }\end{array}$ & No & \begin{tabular}{l}
\multicolumn{1}{r}{ "Po } \\
sición \\
de los \\
medios \\
sobre \\
asuntos \\
judicial \\
es" \\
(artícul \\
o 25 de \\
la Ley \\
Orgánic \\
a de \\
Comuni \\
cación)
\end{tabular} \\
\hline & & & & & & $\begin{array}{l}\quad \text { "Der } \\
\text { echo a } \\
\text { la } \\
\text { rectifica } \\
\text { ción" } \\
\text { (artícul } \\
\text { o } 23 \text { de } \\
\text { la Ley } \\
\text { Orgánic } \\
\text { a de } \\
\text { Comuni } \\
\text { cación) }\end{array}$ \\
\hline $\begin{array}{l}\text { En } \\
\text { lace } \\
\text { Ciuda } \\
\text { dano }\end{array}$ & $\begin{array}{l}\quad \text { No } \\
\text { (el caso } \\
\text { no fue } \\
\text { admitid } \\
\text { o y se } \\
\text { envió al } \\
\text { solicitan }\end{array}$ & $\begin{array}{l}\frac{\text { Notifi }}{\text { cación }} \\
\frac{\text { Trámite }}{\text { No }^{\circ} \text { 038- }} \\
\frac{2014-}{\text { INPS- }} \\
\frac{\text { DNJRD }}{\text { DNJ }}\end{array}$ & $\begin{array}{l}\quad \text { Blasc } \\
\text { o } \\
\text { Peñaherr } \\
\text { era Solah } \\
\text {-director } \\
\text { de la } \\
\text { encuesta }\end{array}$ & \begin{tabular}{l}
\multicolumn{2}{r}{ Supe } \\
rintende \\
ncia de \\
la \\
Informac \\
ión y \\
Comunic
\end{tabular} & Sí & $\begin{array}{l}\text { Ley } \\
\text { Orgánic } \\
\text { a de } \\
\text { Comuni } \\
\text { cación } \\
\text { (artícul } \\
0 \quad 5\end{array}$ \\
\hline
\end{tabular}


Luisa Torrealba Mesa

Impacto de las leyes de comunicación de Ecuador y Venezuela en el

ejercicio de la libertad de expresión, a partir de 6 casos emblemáticos

\begin{tabular}{|c|c|c|c|c|c|c|c|}
\hline & & $\begin{array}{l}\text { te una } \\
\text { notificac } \\
\text { ión } \\
\text { razonad } \\
\text { a de la } \\
\text { SUPER } \\
\text { COM) }\end{array}$ & & $\begin{array}{l}\text { dora } \\
\text { Market y } \\
\text { president } \\
\text { e de la } \\
\text { Cámara } \\
\text { de } \\
\text { Comercio } \\
\text { de Quito }\end{array}$ & $\begin{array}{l}\text { ación } \\
\text { (SUPER } \\
\text { COM) }\end{array}$ & & $\begin{array}{l}\text { Medios } \\
\text { de } \\
\text { comuni } \\
\text { cación } \\
\text { social) }\end{array}$ \\
\hline \multirow[t]{3}{*}{$\begin{array}{l}\text { Ve } \\
\text { nezue } \\
\text { la }\end{array}$} & $\begin{array}{l}\text { NT } \\
\text { N } 24\end{array}$ & \begin{tabular}{l}
\multicolumn{1}{c}{ No, } \\
la \\
decisión \\
de \\
produjo \\
por una \\
orden \\
directa \\
del \\
preside \\
nte de \\
la \\
Repúbli \\
ca
\end{tabular} & $\begin{array}{l}\text { No } \\
\text { se } \\
\text { encontró }\end{array}$ & 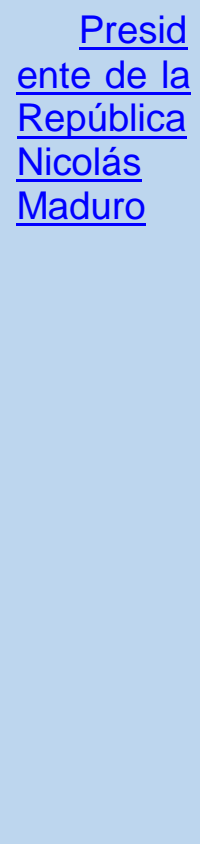 & \begin{tabular}{l}
\multicolumn{1}{r}{ Comi } \\
sión \\
Nacional \\
de \\
Telecom \\
unicacio \\
nes \\
(CONAT \\
EL)
\end{tabular} & \begin{tabular}{l}
\multicolumn{1}{c}{ Sí, } \\
el \\
canal \\
fue \\
sacad \\
o de \\
las \\
parrilla \\
s de \\
las \\
empre \\
sas de \\
televisi \\
ón por \\
suscrip \\
ción \\
de \\
Venez \\
uela.
\end{tabular} & $\begin{array}{l}\quad \text { Ley } \\
\text { de } \\
\text { Respon } \\
\text { sabilida } \\
\text { d Social } \\
\text { en } \\
\text { Radio, } \\
\text { Televisi } \\
\text { ón y } \\
\text { Medios } \\
\text { Electró } \\
\text { nicos } \\
\text { (artícul } \\
\text { o 27) }\end{array}$ \\
\hline & & & & & & $\begin{array}{l}\quad \text { Fu } \\
\text { e } \\
\text { bloque } \\
\text { ado el } \\
\text { acceso } \\
\text { al sitio } \\
\text { web } \\
\text { del } \\
\text { canal } \\
\text { en } \\
\text { Venez } \\
\text { uela }\end{array}$ & \\
\hline & $\begin{array}{r}\text { Gl } \\
\text { obovis }\end{array}$ & Sí & dencia & ión & $\begin{array}{l}\text { Comi } \\
\text { sión }\end{array}$ & Sí & $\begin{array}{r}\text { Pro } \\
\text { hibición }\end{array}$ \\
\hline
\end{tabular}


Luisa Torrealba Mesa

Impacto de las leyes de comunicación de Ecuador y Venezuela en el ejercicio de la libertad de expresión, a partir de 6 casos emblemáticos

\begin{tabular}{|c|c|c|c|c|c|c|}
\hline ión & & $\begin{array}{l}\text { Administr } \\
\text { ativa del } \\
\text { Directori } \\
\underline{\text { o de }} \\
\text { Respons } \\
\text { abilidad } \\
\underline{\text { Social N }{ }^{\circ}} \\
\underline{131}\end{array}$ & $\begin{array}{l}\text { Nacional } \\
\text { de } \\
\text { Telecomu } \\
\text { nicacione } \\
\text { s }\end{array}$ & $\begin{array}{l}\text { Nacional } \\
\text { de } \\
\text { Telecom } \\
\text { unicacio } \\
\text { nes } \\
\text { (CONAT } \\
\text { EL ) }\end{array}$ & & $\begin{array}{l}\text { de } \\
\text { difusión } \\
\text { de } \\
\text { conteni } \\
\text { dos que } \\
\text { "foment } \\
\text { en } \\
\text { zozobra } \\
\text { ) } \\
\text { (Artícul } \\
\text { o } 27 \text { de } \\
\text { la Ley } \\
\text { de } \\
\text { Respon } \\
\text { sabilida } \\
\text { d Social } \\
\text { en } \\
\text { Radio } \\
\text { Televisi } \\
\text { ón y y } \\
\text { Medios } \\
\text { Electró } \\
\text { nicos) } \\
\end{array}$ \\
\hline $\mathrm{NN}^{\mathrm{C}}$ & \begin{tabular}{l}
\multicolumn{1}{c}{ Sí, } \\
fue \\
abierto \\
un \\
procedi \\
miento \\
adminis \\
trativo \\
sancion \\
atorio, \\
pero \\
vino \\
acompa \\
ñado de \\
una \\
medida \\
cautelar \\
que \\
vulneró \\
el \\
derecho
\end{tabular} & $\begin{array}{l}\frac{\text { Com }}{\text { unicado }} \\
\frac{\text { de la la }}{\text { Comisión }} \\
\frac{\text { Nacional }}{\text { de }} \\
\frac{\text { Telecom }}{\text { unicacio }} \\
\underline{\text { nes }}\end{array}$ & $\begin{array}{l}\frac{\text { Presid }}{\text { ente de la }} \\
\frac{\text { República }}{\text { Nicolás }} \\
\underline{\text { Maduro }}\end{array}$ & \begin{tabular}{l}
\multicolumn{1}{r}{ Comi } \\
sión \\
Nacional \\
de \\
Telecom \\
unicacio \\
nes \\
(CONAT \\
EL )
\end{tabular} & \begin{tabular}{l}
\multicolumn{1}{r}{ Sí, } \\
el \\
canal \\
fue \\
sacad \\
o de \\
las \\
parrilla \\
s de \\
las \\
empre \\
sas de \\
televisi \\
ón por \\
suscrip \\
ción \\
de \\
Venez \\
uela.
\end{tabular} & $\begin{array}{l}\text { Ley } \\
\text { de } \\
\text { Respon } \\
\text { sabilida } \\
\text { d Social } \\
\text { en } \\
\text { Radio, } \\
\text { Televisi } \\
\text { ón y } \\
\text { Medios } \\
\text { Electró } \\
\text { nicos } \\
\text { (no cita } \\
\text { ningún } \\
\text { artículo } \\
\text { en } \\
\text { particul } \\
\text { ar) }\end{array}$ \\
\hline
\end{tabular}




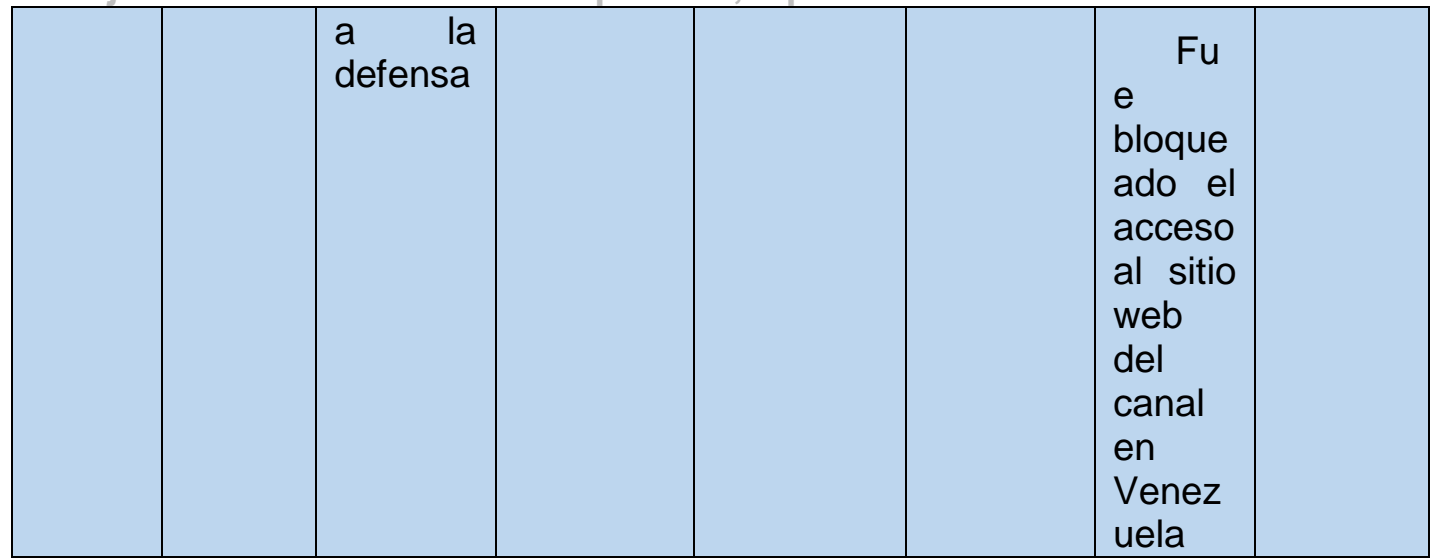

Fuente: Elaboración propia

Como se aprecia en el cuadro, en los casos fueron abiertos procedimientos por parte de los organismos con competencia en área de comunicación, con excepción del caso de NTN 24, cuya salida del aire fue ordenada de forma directa por el propio presidente venezolano Nicolás Maduro.

Las críticas públicas y advertencias del propio presidente de la República hacia NTN 24, Globovisión y CNN, mostraron baja tolerancia a la crítica y a la divulgación de información, que dejó en evidencia la falta de acción por parte del gobierno para atender problemas que aquejan a la ciudadanía, como lo demostró el programa censurado en Globovisión que daba cuenta de la situación de escasez de alimentos que afecta a Venezuela.

\section{Discusión y conclusiones}

Luego de revisar exhaustivamente de los casos de estudio, se constató que la aplicación de la Ley Orgánica de Comunicación (Ecuador) y la Ley de Responsabilidad Social en Radio, Televisión y Medios Electrónicos (Venezuela), han impactado negativamente el ejercicio de la libertad de expresión en Ecuador y Venezuela, toda vez que violaron garantías de los ciudadanos, contempladas en el derecho internacional, a expresar críticas, ideas y opiniones que, como ha puntualizado Mónica Pinto (2000), son condiciones necesarias para el ejercicio pleno de la libertad de expresión.

De acuerdo a lo explicado por Janeth Kelly (2003), las leyes vigentes definen los lineamientos de las políticas públicas de un país. Entonces, la existencia de legislaciones punitivas y restrictivas, para el sector comunicaciones, tanto en 
Impacto de las leyes de comunicación de Ecuador y Venezuela en el

ejercicio de la libertad de expresión, a partir de 6 casos emblemáticos

Ecuador como en Venezuela, son indicadores de políticas o estrategias gubernamentales adversas a la crítica y a la pluralidad.

La prohibición de divulgar contenidos que puedan desprestigiar o reducir la credibilidad pública de una persona, sustentada en el concepto "linchamiento mediático", del artículo 26 de la LOC, puede resultar contraria a "la libertad de buscar, recibir y difundir informaciones e ideas de toda índole", contemplada en la Convención Americana de Derechos Humanos.

Además, el concepto linchamiento mediático es ambiguo. Como advirtió el Relator Especial para la Libertad de Expresión, Edison Lanza (2016), dicho concepto le otorga discreción a las autoridades políticas para restringir contenidos de los medios de comunicación considerados críticos, impidiendo el libre y plural flujo de ideas y opiniones necesarios para la democracia.

La obligación de presentar una disculpa pública, aplicada a Teleamazonas, fundamentada en el concepto linchamiento mediático, creó un precedente negativo que podría generar nuevas acciones orientadas a censurar la crítica.

El caso de la multa por US\$90 mil al diario El Universo, por la difusión de una caricatura, constituyó una vía o medio indirecto, para limitar la libertad de expresión, prohibido expresamente en el artículo 13 de la Convención Americana de Derechos Humanos. Si bien se trató de una medida económica y no de censura directa, la misma configuró una acción de presión, cuyo fin último fue evitar que el medio siguiera emitiendo opiniones o informaciones sobre el allanamiento de la residencia del periodista Fernando Villavicencio, por parte de miembros de cuerpos de seguridad del Estado.

Este tipo de acciones pueden ocasionar que medios de comunicación se autocensuren para evitar sanciones similares, o impactar la operatividad de las empresas de comunicación masiva, al obligarlas a reducir su personal o sus espacios informativos, para abaratar costos y poder sobreponerse del impacto de las multas.

Otro agravante en este caso fue que el procedimiento se abrió luego de que el presidente de la República acusara al caricaturista en su programa "Enlace Ciudadano" $\mathrm{N}^{\circ} 355$ de ser un "sicario de tinta y enfermo" y amenazó con aplicarle la Ley de Comunicación por la referida caricatura.

En el caso del programa presidencial Enlace Ciudadano, la decisión de la SUPERCOM, en respuesta al pedido del empresario Blasco Peñaherrera, vulneró el derecho a la réplica, consagrado tanto en el artículo 66 de la Constitución de Ecuador (Asamblea Nacional Constituyente del Ecuador, 2008) y 24 de la ley Orgánica de Comunicación (ver programa Enlace Ciudadano № 362 


\section{Impacto de las leyes de comunicación de Ecuador y Venezuela en el}

ejercicio de la libertad de expresión, a partir de 6 casos emblemáticos

del 22 de febrero de 2014 - desde 3:15:58' a 3:18:00'-); y protegió al presidente ecuatoriano, en detrimento de un ciudadano que se sintió afectado por contenidos difundidos por Rafael Correa en su espacio televisivo. Por otro lado, implicó una acción de cesura que contravino las garantías para la libertad de expresión consagrada en el artículo 13 de la Convención Americana de Derechos Humanos y el artículo 384 de la Constitución de Ecuador.

En Venezuela, la prohibición de contenidos que generen "zozobra", establecida en el artículo 27 de la Ley Responsabilidad Social en Radio, Televisión y Medios Electrónicos, constituye un concepto que no está incorporado en las limitaciones a la libertad de expresión incluidas en los instrumentos internacionales de derechos humanos y que implica la censura de contenidos, que está prohibida en la Constitución venezolana.

En los casos de Globovisión, CNN y NTN 24 la aplicación del artículo 27 de la Ley RESORTE que fomenta la censura, se contradice con el espíritu de la Constitución venezolana y del artículo 13 de la Convención Americana de Derechos Humanos que la prohíben, y con el propio objetivo de la ley que promete de defensa de la libertad de expresión.

La ambigüedad del concepto "zozobra" permitió que la CONATEL ordenara la salida del aire de la cadena CNN, y abriera un procedimiento sancionatorio contra el canal Globovisión, con la posible aplicación de sanciones por la transmisión de informaciones sobre la escasez de alimentos en Venezuela y que el presidente Maduro, sin tener facultades legales para ello, decidiera la salida del aire del canal colombiano NTN 24. En los tres casos, las actuaciones implicaron censura por la transmisión hecha por las televisoras de contenidos de interés público que dejaron en evidencia las irregularidades o problemas derivados de fallas en las actuaciones del gobierno nacional, que resultaron incómodas para las autoridades.

Estas restricciones confirman la primera hipótesis planteada para esta investigación: La Ley Orgánica de Comunicación (Ecuador) y la Ley de Responsabilidad Social en Radio, Televisión y Medios Electrónicos (Venezuela) han limitado el ejercicio del derecho de la libertad de expresión en sus respectivos países.

Por otro lado, la presencia de garantías para la libertad de expresión en las constituciones nacionales de Ecuador y Venezuela (en los artículos 384 y 57, respectivamente), constituyen un buen punto de partida para el ejercicio de este 


\section{Impacto de las leyes de comunicación de Ecuador y Venezuela en el}

ejercicio de la libertad de expresión, a partir de 6 casos emblemáticos

derecho en ambos países. No obstante, la presencia de conceptos ambiguos, en ambas legislaciones, que han servido de argumento para la aplicación de sanciones (como el de "linchamiento mediático" en la Ley Orgánica de Comunicación de Ecuador y la prohibición de contenidos que "generen zozobra", en la Ley de Responsabilidad Social en Radio, Televisión y Medios Electrónicos en Venezuela), demuestran contradicciones que resultan desfavorables para el derecho y permiten la actuación discrecional de las autoridades, para censurar contenidos que consideren incómodos.

Al incluir disposiciones para censurar o restringir la libre expresión de ideas, pensamiento y opiniones, en sus leyes de comunicación, los estados de Ecuador y Venezuela suprimen los sistemas de frenos y contrapesos a los poderes públicos, necesarios en sistemas democráticos, como lo explicó Gerardo Munck (2010).

Estas contradicciones confirman la segunda hipótesis planteada en esta investigación: Las disposiciones sobre el ejercicio de la libertad de expresión, contenidas en la Ley Orgánica de Comunicación (Ecuador) y en la Ley de Responsabilidad Social en Radio, Televisión y Medios Electrónicos (Venezuela), no son coherentes con las garantías establecidas en las constituciones de estos países para garantizar este derecho.

En los casos que fueron estudiados en la presente investigación se afectó tanto la dimensión individual de la libertad de expresión como la dimensión colectiva a las que refiere Luis Huertas. De forma individual fueron afectados los autores o responsables de los contenidos mediáticos sobre los que se aplicaron las medidas de censura. $Y$ en el aspecto colectivo fueron afectadas todas las personas que conforman la audiencia de los medios que difundieron dichos contenidos. Las restricciones encontradas en los casos violaron el derecho y la libertad de buscar, recibir y difundir informaciones e ideas "de toda índole", amparadas en el artículo 13 de la Convención Americana de Derechos Humanos.

Dentro de ese derecho de difusión de ideas de toda índole resulta fundamental la crítica o la posibilidad de opinar sobre asuntos de interés general, necesarios para nutrir el debate público, como lo refiere Réniz (2002). Los casos analizados tuvieron como elemento común que hacían referencia a asuntos públicos o que involucraban a funcionarios o personalidades públicas; con lo cual, al limitarlo o censurarlo, mediante la aplicación de las leyes, se restringió el pluralismo y la libertad de las audiencias para recibir información, opinar y tomar sus propias decisiones sobre dichos asuntos. Y se impuso una política unilateral 
Impacto de las leyes de comunicación de Ecuador y Venezuela en el

ejercicio de la libertad de expresión, a partir de 6 casos emblemáticos que apuntó a la opacidad o a silenciar asuntos que le resultaran incómodos a figuras de poder.

Estos casos muestran un uso discrecional de ambas leyes orientado a silenciar cualquier información considerada crítica por quienes ejercen el poder político y tienen atribuciones sancionatorias sobre los medios, lo que corrobora que la Ley Orgánica de Comunicación (Ecuador), y la Ley de Responsabilidad Social en Radio, Televisión y Medios Electrónicos (Venezuela) han limitado el ejercicio del derecho de la libertad de expresión en sus respectivos países.

\section{Referencias bibliográficas}

Asamblea Nacional de la República Bolivariana de Venezuela (2009). Constitución de la República Bolivariana de Venezuela. Gaceta Oficial de la República Bolivariana de Venezuela, № 5.908 (Extraordinario), 19-02-2009.

Asamblea Nacional de la República Bolivariana de Venezuela (2011). Ley de Reforma parcial de la Ley de Responsabilidad Social en Radio, Televisión y Medios Electrónicos. Gaceta Oficial de la República Bolivariana de Venezuela, № 39.610, 07-02-2011.

Asamblea Nacional de Ecuador (2013). Ley Orgánica de Comunicación. Registro Oficial. Órgano del Gobierno del Ecuador, Año I, N²22, 25-06-2013.

Asamblea Nacional Constituyente del Ecuador (2008). Constitución de la República del Ecuador 2008. Registro Oficial № 449, 20-10-2008.

Botero Catalina (2010). Informe Anual de la Comisión Interamericana de Derechos Humanos 2010. Informe de la Relatoría Especial para la Libertad de Expresión.

En: http://www.oas.org/es/cidh/expresion/docs/informes/anuales/Informe\%20Anual\% 202010\%20ESPI.pdf. Consulta: 1 de agosto de 2017.

CNN (2017a). El Gobierno de Venezuela retira la señal de CNN en Español del aire. En: http://cnnespanol.cnn.com/2017/02/15/gobierno-de-venezuela-retirasenal-de-cnn-en-espanol/. Consulta: 3 de agosto de 2017.

CNN (2017b). Pasaportes en la sombra. Pasaportes venezolanos, ¿en manos equivocadas? En: http://cnnespanol.cnn.com/2017/02/06/pasaportesvenezolanos-en-manos-equivocadas/. Consulta: 3 de agosto de 2017

CONATEL (2014). William Castillo: "No permitiremos que se use el espectro radioeléctrico para otro golpe de Estado". En: http://www.CONATEL 

gob.ve/william-castillo-no-permitiremos-que-se-use-el-espectro-radioelectricopara-otro-golpe-de-estado/. Consulta: 18 de junio de 2017.

CONATEL (2017). CONATEL abre procedimiento administrativo sancionatorio en virtud de transmisión de la señal de CNNEE. En:

http://www.CONATEL .gob.ve/CONATEL -al-pais-2/. Consulta: 5 de agosto de 2017.

Corte Interamericana de Derechos Humanos (1985). Opinión Consultiva OC5/85 de la Corte Interamericana de Derechos Humanos, sobre La Colegiación

Obligatoria de Periodistas. En: http://www.corteidh.or.cr/docs/opiniones/seriea_05_esp.doc. Consulta: 5 de julio de 2017

Dream Team (2014a). Dream Team primer bloque, 19 de octubre. En: https://www.youtube.com/watch?v=2UqYPyHFcqY. Consulta: 25 de julio de 2017.

Dream Team (2014b). Dream Team primer bloque, 16 noviembre. En: https://www.youtube.com/watch?v=40u_UEERK5c. Consulta: 25 de julio de 2017.

Enlace Ciudadano (2014a). Enlace Ciudadano Nro. 355. En: http://enlaceciudadano.gob.ec/prueba/nro-355/. Consulta: 20 de julio de 2017.

Enlace Ciudadano (2014b). Enlace Ciudadano Nro. 362. En: http://enlaceciudadano.gob.ec/prueba/enlaceciudadano362/. Consulta: 20 de julio de 2017.

Fundamedios (2014a). Caricaturista y medio sancionados bajo Ley de Comunicación. En: http://www.fundamedios.org/alertas/caricaturista-y-mediosancionados-bajo-ley-de-comunicacion/. Consulta: 5 de junio de 2017.

Fundamedios (2014b). Fundamedios deplora resolución inconstitucional de Supercom que consagra la imposibilidad de réplica en sabatinas. En: http://www.fundamedios.org/alertas/fundamedios-deplora-resolucioninconstitucional-de-supercom-que-consagra-la-imposibilidad-de-replica-ensabatinas/. Consulta: 5 de junio de 2017.

Fundamedios (2015). Primera sanción por "linchamiento mediático". En: http://www.fundamedios.org/alertas/primera-sancion-por-linchamiento-mediatico/. Consulta: 1 de junio de 2017. 
Fundamedios (2017). Tipos de ataques a la libertad de expresión. En: http://www.fundamedios.org/. Consulta: 15 de septiembre 2017.

HUERTA, L. (2002) Libertad de Expresión y acceso a la información pública. Lima: Comisión Andina de Juristas.

IPYS Venezuela (2013). Inician acción administrativa contra televisora por generar zozobra. En: http://ipysvenezuela.org/alerta/caracas-inician-accionadministrativa-contra-televisora-por-generar-zozobra/. Consulta: 25 de julio de 2017.

IPYS Venezuela (2014a). Ordenaron sacar señal de canal internacional NTN24 de empresas que ofrecen servicio de radio y TV por suscripción. En: http://ipysvenezuela.org/alerta/caracas-ordenaron-sacar-senal-de-canalinternacional-ntn24-de-empresas-que-ofrecen-servicio-de-radio-y-tv-porsuscripcion/. Consulta: 15 de julio de 2017

IPYS Venezuela (2014b). Nicolás Maduro reconoció haber ordenado sacar señal del canal NTN24 de las empresas que ofrecen servicio en radio y televisión por suscripción. En: http://ipysvenezuela.org/alerta/caracas-nicolas-maduroreconocio-haber-ordenado-sacar-senal-del-canal-ntn24-de-las-empresas-queofrecen-servicio-en-radio-y-television-por-suscripcion/. Consulta: 15 de julio de 2017.

IPYS Venezuela (2017). Conatel saca del aire a CNN en Español por orden presidencial. En: http://ipysvenezuela.org/alerta/conatel-saca-del-aire-cnnespanol-orden-presidencial/. Consulta 24 de julio de 2017.

Kelly, Janeth (2003). Políticas públicas en América Latina. Teórica y práctica. Caracas: IESA, p. 72

Lanza Edison (2016). Informe Anual de la Comisión Interamericana de Derechos Humanos 2016 Volumen II. Informe de la Relatoría Especial para la Libertad de Expresión. En: http://www.oas.org/es/cidh/expresion/docs/informes/anuales/InformeAnual2016R ELE.pdf. Consulta: 1 de agosto de 2017.

Munck, Gerardo (2010). "Repensando la cuestión democrática: la región andina en el nuevo siglo". Revista de Ciencia Política, 30, p. 156. En: http://www.redalyc.org/articulo.oa?id=32414670008. Consulta: 28 de julio de 2017. 
Impacto de las leyes de comunicación de Ecuador y Venezuela en el

ejercicio de la libertad de expresión, a partir de 6 casos emblemáticos

NTN 24 (2014). Bonil: "Cuando el poder te manda rectificar tu caricatura, estás haciendo bien tu trabajo". En: https://www.youtube.com/watch?v=y5Ya2QoFaE. Consultada: 2 de agosto de 2017.

Noticias Venezuela (2014). Maduro sobre NTN24 "Fuera del aire". En: https://www.youtube.com/watch?v=BRGPLO6izaY. Consulta: 5 de agosto de 2017.

OEA (1969). Convención Americana de Derechos Humanos. En: https://www.oas.org/dil/esp/tratados b-

32_convencion_americana_sobre_derechos_humanos.htm. Consulta 18 de julio de 2017.

Pinto, Mónica (2000). “Libertad de Expresión y derecho a la información como derechos humanos". Estudios Básicos de Derechos Humanos (Volumen X). San José de Costa Rica: Instituto Interamericano de Derechos Humanos, pp. 17-47.

RÉNIZ CABALLERO, D. (2002) Los Derechos de la Información y de la Comunicación. Panorama general. Una visión internacional. Bogotá: Fundación Konrad Adenauer Stiftung/ Asociación Iberoamericana de Derecho de la Información y de la Comunicación/ Pontificia Universidad Javeriana.

SUPERCOM (2014a). Resolución $N^{\circ}$ 001-2014-DNGJPO. En: http://www.supercom.gob.ec/es/marco-juridico/resoluciones/2014?site=8.

Consultada: 10 de julio de 2017.

SUPERCOM (2014b). Trámite N $N^{\circ}$ 038-2014-INPS-DNJRD. En: http://pasionporlademocracia.com/wpcontent/uploads/2014/01/Respuesta\%20SUPERCOM.pdf. Consultada: 12 de julio de 2017.

SUPERCOM (2015). Resolución No 010-2015-DNJRD. En: http://www.supercom.gob.ec/es/marco-juridico/resoluciones/2015/160-resol-0102015-dnjird. Consultada: 12 de julio de 2017.

Venezuela Lucha (2014). NTN24 Venezuela 12-Febrero. En: https://www.youtube.com/watch?v=00JBpcuD03A. Consultada: 1 de agosto de 2017. 
Impacto de las leyes de comunicación de Ecuador y Venezuela en el ejercicio de la libertad de expresión, a partir de 6 casos emblemáticos
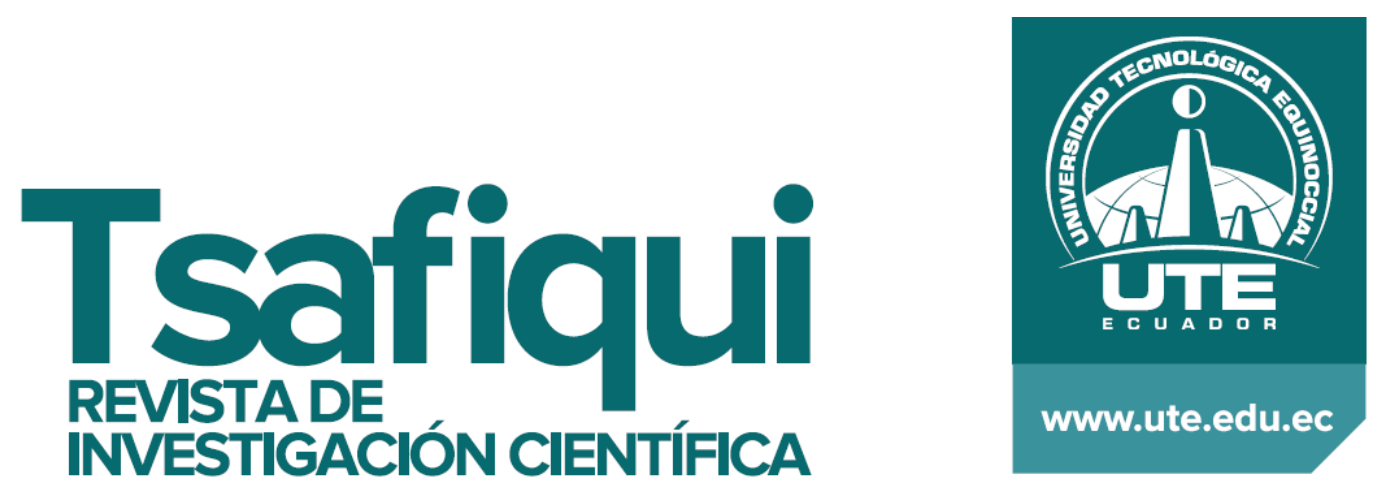